Research Article

\title{
Mixing Ratios and Cementing Mechanism of Similar Silty Mudstone Materials for Model Tests
}

\author{
Hong-Yuan Fu, ${ }^{1}$ Shuang-Xing Qi $\mathbb{D},{ }^{2}$ Zhen-Ning Shi $\mathbb{D},{ }^{3}$ and Ling Zeng $\mathbb{C}^{2}$ \\ ${ }^{1}$ School of Civil Engineering, National Engineering Laboratory of Highway Maintenance Technology, \\ Changsha University of Science \& Technology, Changsha 410114, China \\ ${ }^{2}$ School of Civil Engineering, Changsha University of Science \& Technology, Changsha 410114, China \\ ${ }^{3}$ School of Traffic \& Transportation Engineering, National Engineering Laboratory of Highway Maintenance Technology, \\ Changsha University of Science \& Technology, Changsha 410114, China
}

Correspondence should be addressed to Ling Zeng; z1001@csust.edu.cn

Received 8 April 2021; Accepted 31 July 2021; Published 18 August 2021

Academic Editor: Guoyang Lu

Copyright ( 2021 Hong-Yuan Fu et al. This is an open access article distributed under the Creative Commons Attribution License, which permits unrestricted use, distribution, and reproduction in any medium, provided the original work is properly cited.

The similarity model test is one of the important means to study the engineering properties of soft rock. This study aims to develop similar materials for silty mudstone, which has characteristics of low strength and water expansion, based on traditional materials including gypsum, barite powder, clay minerals, and distilled water. The orthogonal design method was used to determine the mixing ratios of the similar materials. The density, uniaxial compressive strength, tensile strength, elastic modulus, and Poisson's ratio were selected as control indicators of the similar materials. The results show that the water content is the dominant factor for the density, tensile strength, elastic modulus, and Poisson's ratio of the similar materials of silty mudstone, while the gypsum content is the dominant factor for the uniaxial compressive strength. The physical and mechanical properties of the similar material samples with water content of $19 \%$, barite powder ratio of $32 \%$, and gypsum mass of $250 \mathrm{~g}$ show good similarity to those of the raw silty mudstone. The water absorption and expansibility of similar materials with clay mineral ratio of $12 \%$ are consistent with those of the raw silty mudstone. The scanning electron microscopy (SEM) observation indicates that the similar material with optimal mixing ratios exhibits a similar microstructure to that of silty mudstone.

\section{Introduction}

Silty mudstone shows obvious characteristics of water absorption and expansion, so its mechanical properties deteriorate easily under a long-term influence of rainfall. As a result, instability often takes place in silty mudstone slopes, which is a major geological problem encountered in the engineering construction in southern China [1-3]. In geotechnical tests, intact samples are often required in order to better consider the influences of single factor or multiple factors. However, natural silty mudstone usually contains numerous joints and fissures due to weathering. Thus, it is difficult to extract completely intact samples without initial random damage. Moreover, the preparation of undisturbed raw samples is quite expensive because of the need for highprecision equipment. If the physical and mechanical properties are measured from raw rock samples with unknown initial damages, they are not suitable to be used in numerical simulations and guiding practical engineering. Also, because of complicated practical conditions, there are few applicable and cheap field testing approaches for the determination of physical and mechanical properties of silty mudstone.

By contrast, the use of similar materials enables not only eliminating the influence of initial damage but also prefabricating fractures. In this way, the influence of different fracture morphology on the strength of rock mass can be analyzed [4-6]. Since similar materials have many advantages, they are widely employed to study the influence of single factor and multiple factors on many scientific problems [7]. For instance, similar materials were employed to prepare specimens for laboratory tests to determine the 
physical and mechanical properties of rocks, which are important input parameters for numerical simulations $[8,9]$. Similar materials can also be adopted to prepare physical models for similarity model tests, so the connection between models and prototypes can be identified $[10,11]$. Finally, the engineering performance of the prototype can be predicted according to the similarity criterion $[12,13]$.

In recent years, the research results of similar materials of different types of rocks show that the key to improve the similarity between similar materials and raw rocks is to choose the right raw materials and adopt reasonable proportions [14-16]. For example, Yang et al. [17], Chen and Fen [18], Wang et al. [19], Liu and Liu [20], and He et al. [21] among others studied the mixing ratios of similar materials for different types of soft rocks, such as red-bed soft rock, carbonaceous phyllite rock, and coal rock. The above scholars first selected appropriate raw materials and used orthogonal tables to design the mixing ratios of similar materials. Secondly, uniaxial compression tests, splitting tests, and triaxial compression tests were conducted to measure the physical and mechanical properties of similar materials. Then, compared with different types of target rocks, similar rock-like materials suitable for various types of target rocks were determined. Finally, the optimal mixing ratio that satisfies the similarity was obtained [22, 23]. In addition, Wang et al. [24] carried out creep tests on the similar developed materials of a soft rock. The authors stated that the creep parameters of similar materials basically met the similarity with the raw rock by parameter inversion, laying a foundation for similar materials to simulate the creep characteristics of the soft rock. Chu et al. [25] developed a similar material that conforms to the rheology of soft rock, which can be used to simulate the rheological characteristics of soft sandy mudstone. Although the scholars mentioned above have studied the similar materials of soft rocks and their related characteristics, the research on the characteristics of water absorption and expansion of similar materials for soft rocks is rarely involved.

In the process of designing similar materials, the cementation is an important means to make similar material samples reach the strength of the raw rock. Gypsum, as a common cementing material, is widely used in the development of similar materials of soft rocks. Existing studies have shown that the strength of similar materials formed by gypsum cementation can simulate the diagenetic strength of various raw rocks under geological actions $[26,27]$. In addition, some scholars have carried out many investigations of the cementation of clay minerals. For instance, Xie et al. [28] analyzed the microstructure of attapulgite by scanning electron microscopy (SEM); they concluded that the cementation performance of clay minerals was inseparable from the microstructure. Yang et al. [29] analyzed the microstructure of cementing products by means of SEM. Therefore, the similar materials formed by cementation can meet the requirements of simulating the strength of raw soft rocks, and the cementation mechanism can be revealed via SEM.

This paper presents an experimental work to develop similar materials of silty mudstone for physical model tests. Gypsum and barite powder are selected as the cementing material and aggregate, respectively, and clay minerals (i.e., illite, montmorillonite, and chlorite) are used as swelling additives. Firstly, a series of mixing ratios are designed according to an orthogonal table. Secondly, the physical and mechanical properties of similar materials of various mixing ratios are studied by laboratory tests; the influences of different factors on the properties are examined by sensitive analysis. Afterward, the water absorption and expansibility of similar materials are measured. Therefore, the mixing ratios that can satisfy the mechanical properties and the water-expansion characteristic of silty mudstone are obtained. Finally, the cementing mechanism of similar materials of silty mudstone is revealed by SEM. The similar developed material can well simulate the engineering behavior of silty mudstone, which lays a foundation for the similarity model tests of engineering cases involved in silty mudstone.

\section{Design of Similar Materials}

2.1. Similarity Ratio. The dimensional analysis method was used to determine the similarity ratios of properties of the similar material to those of the raw rock. Based on the three basic dimensions, that is, length $(\mathrm{L})$, time $(\mathrm{T})$, and mass $(\mathrm{M})$, the dimensions of other important physical and mechanical properties were deduced. In this study, the similarity ratios in terms of length $(\mathrm{L})$, time $(\mathrm{T})$, and mass $(\mathrm{M})$ are considered to be 1 , which means the length, time, and mass involving similar materials are exactly the same as those of the raw rock. Then, the similarity ratios of other properties can be obtained, as shown in Table 1. Therefore, the target properties of similar materials are derived from the properties of the raw rock based on the similarity ratios $[13,14]$.

2.2. Material Selection. The strongly weathered silty mudstone collected from the Yuelu Mountain (Changsha, China) was selected as the prototype. $\mathrm{X}$-ray diffraction analysis showed that silty mudstone is mainly composed of quartz, illite, montmorillonite, chlorite, and feldspar, as shown in Figure 1 and Table 2. According to Editorial Board of Engineering Geology Handbook [30], the density, uniaxial compressive strength, tensile strength, elastic modulus, and Poisson's ratio are the most important properties of silty mudstone. Thus, these physical and mechanical properties were used as the controlling indicators to design similar materials (see Table 3).

Previous studies showed the possibility to produce similar materials of rocks with gypsum, barite powder, and clay $[26,27,31]$. Therefore, barite powder, gypsum, and clay minerals were selected to develop similar materials of silty mudstone. Among the above materials, barite powder works as aggregate, gypsum serves as the cementing agent, and clay minerals (montmorillonite $:$ illite $:$ chlorite $=1: 0.14: 0.23$, which is consistent with proportions of the raw rock)) are used as swelling additives to control the water-absorption and water-expansion characteristics of similar materials. Deionized water was also adopted to form similar materials. The grain size distributions of the above raw materials are shown in Figure 2. 
TABLE 1: Dimensional analysis.

\begin{tabular}{lccc}
\hline Property & Dimension & Similar relationship & Similarity ratio \\
\hline Length & $(\mathrm{L})$ & $C_{\mathrm{L}}$ & 1 \\
Time & $(\mathrm{T})$ & $C_{\mathrm{T}}$ & 1 \\
Mass & $(\mathrm{M})$ & $C_{\mathrm{M}}$ & 1 \\
Density & $(\mathrm{M})(\mathrm{L})^{-3}$ & $C_{\rho}$ & 1 \\
Tensile strength & $(\mathrm{M})(\mathrm{L})^{-1}(\mathrm{~T})^{-2}$ & $\mathrm{C}_{\mathrm{M}} \mathrm{C}_{\mathrm{T}}^{-1} \mathrm{C}_{\mathrm{L}}^{-2}$ & 1 \\
Uniaxial compressive strength & $(\mathrm{M})(\mathrm{L})^{-1}(\mathrm{~T})^{-2}$ & $\mathrm{C}_{\mathrm{M}} \mathrm{C}_{\mathrm{T}}^{-1} \mathrm{C}_{\mathrm{L}}^{-2}$ & 1 \\
Modulus of elasticity & $(\mathrm{M})(\mathrm{L})^{-1}(\mathrm{~T})^{-2}$ & $\mathrm{C}_{\mathrm{M}} \mathrm{C}_{\mathrm{T}}^{-1} \mathrm{C}_{\mathrm{L}}^{-2}$ & 1 \\
Poisson's ratio & $(1)$ & 1 & 1 \\
\hline
\end{tabular}

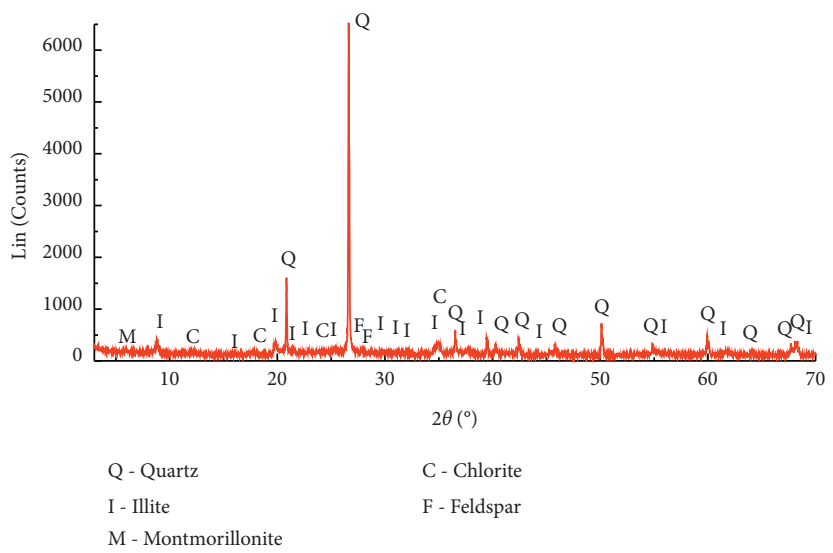

FIGURE 1: X-ray diffraction pattern of silty mudstone.

TABLE 2: Mineral compositions of silty mudstone.

\begin{tabular}{lccccc}
\hline Quartz (\%) & Illite (\%) & Montmorillonite (\%) & Chlorite (\%) & Feldspar (\%) & Other (\%) \\
\hline 49.3 & 27.1 & 3.7 & 6.3 & 4.1 & $<1$ \\
\hline
\end{tabular}

TABLE 3: Main physical and mechanical properties of silty mudstone.

\begin{tabular}{lcccc}
\hline Density $\rho\left(\mathrm{g} / \mathrm{cm}^{3}\right)$ & Uniaxial compressive strength $\sigma_{\mathrm{c}}(\mathrm{MPa})$ & Tensile strength $\sigma_{\mathrm{t}}(\mathrm{MPa})$ & Modulus of elasticity $E(\mathrm{GPa})$ & Poisson's ratio $\nu$ \\
\hline 2.01 & 13.95 & 1.24 & 1.38 & 0.22 \\
\hline
\end{tabular}

2.3. Orthogonal Design Scheme. The orthogonal design was employed to study the mixing ratios in order to improve the efficiency of developing similar materials. The evaluated properties included the density, uniaxial compressive strength, tensile strength, elastic modulus, and Poisson's ratio. The orthogonal test design is an efficient, fast, and economic method for experimental design with the consideration of multiple factors and levels [32]. With this method, one can obtain the best combination of levels for different factors with a small number of samples based on an orthogonal array.

Because the content of every component has a dominant influence on the physical and mechanic properties of similar materials [13], the water content, barite powder ratio, gypsum mass, and clay mineral ratio were chosen as factors in the orthogonal test design. The barite powder ratio is the ratio of the mass of barite powder to the total mass of gypsum and barite powder, and the clay mineral ratio is the mass ratio of clay minerals to all solid components. After a large number of trial tests, the suitable levels of the four factors that could make similar materials have close physical and mechanical properties as the raw rock are as follows: water content (factor $\mathrm{A})=23 \%-17 \%$, barite powder ratio (factor B) $=44 \%-26 \%$, gypsum mass (factor C) = $225 \mathrm{~g}-300 \mathrm{~g}$, and clay mineral ratio (factor D) $=0 \%-18 \%$.

The specific experimental schemes are shown in Table 4. During the experiment, each test scheme was repeated four times, and the average value was taken for analysis. Since the materials were reconstituted artificial rocks that had quite homogeneous structures, four parallel tests were basically enough to characterize their main properties $[19,33]$.

2.4. Secondary Refinement Test Scheme. Silty mudstone has obvious water-absorption and water-expansion characteristics. Some scholars pointed out that the disintegration of mudstone is caused by water expansion of rock, dissolution of cementing substance, and wetting-heating cycles [34].

It was reported that clay minerals have a great influence on water absorption and expansion of soils [35]. Thus, secondary refinement test schemes were considered in order 


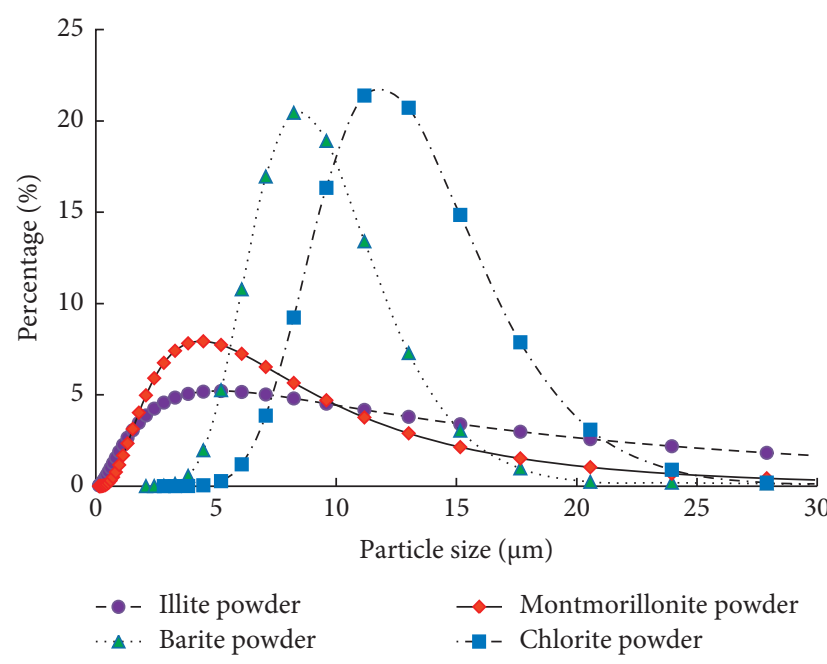

(a)

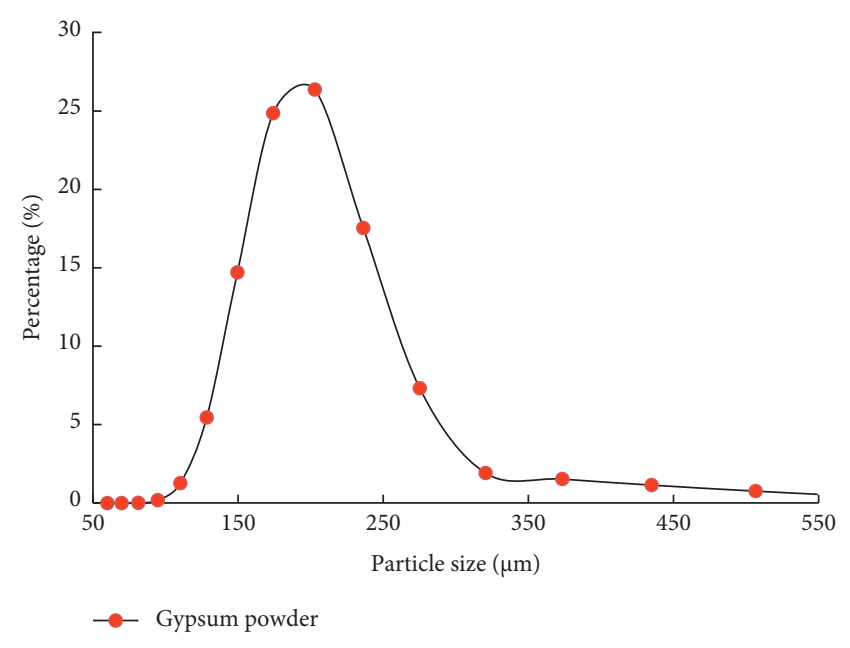

(b)

Figure 2: Particle size distributions of different raw materials: (a) clay minerals and barite powder; (b) gypsum powder.

TABLE 4: Experimental scheme.

\begin{tabular}{|c|c|c|c|c|}
\hline \multirow{2}{*}{ Scheme } & \multicolumn{4}{|c|}{ Factor } \\
\hline & A (water content, \%) & B (barite powder ratio, \%) & $\mathrm{C}$ (gypsum mass, g) & $\mathrm{D}$ (clay mineral ratio, $\%)$ \\
\hline 1 & $23($ level 1) & $44($ level 1$)$ & $225($ level 1) & $0($ level 1$)$ \\
\hline 2 & 23 & 38 (level 2) & 250 (level 2) & 6 (level 2) \\
\hline 3 & 23 & 32 (level 3) & 275 (level 3) & 12 (level 3) \\
\hline 4 & 23 & 26 (level 4) & 300 (level 4) & 18 (level 4) \\
\hline 5 & 21 (level 2) & 44 & 250 & 12 \\
\hline 6 & 21 & 38 & 225 & 18 \\
\hline 7 & 21 & 32 & 300 & 0 \\
\hline 8 & 21 & 26 & 275 & 6 \\
\hline 9 & 19 (level 3) & 44 & 275 & 18 \\
\hline 10 & 19 & 38 & 300 & 12 \\
\hline 11 & 19 & 32 & 225 & 6 \\
\hline 12 & 19 & 26 & 250 & 0 \\
\hline 13 & 17 (level 4) & 44 & 300 & 6 \\
\hline 14 & 17 & 38 & 275 & 0 \\
\hline 15 & 17 & 32 & 250 & 18 \\
\hline 16 & 17 & 26 & 225 & 12 \\
\hline
\end{tabular}

to examine the water-absorption and water-expansion characteristics of similar materials at varying factor D (clay mineral ratio) (Table 5). If the relationship between the water-absorption and water-expansion characteristics and clay mineral ratios is determined, the design of a similar material that has the same water-absorption and waterexpansion characteristics as the raw rock can be realized by simply adjusting the clay mineral ratio. Water-absorption tests and expansibility tests were carried out to measure the water-absorption and water-expansion characteristics.

\section{Experimental Details}

3.1. Sample Preparation. A standardized method was designed to reduce the interference of human factors in the process of sample preparation. According to the IRSM [36], cylindrical samples for uniaxial compression tests had diameters of $50 \mathrm{~mm}$ and heights of $50 \mathrm{~mm}$, and those for splitting tests had diameters of $50 \mathrm{~mm}$ and heights of $100 \mathrm{~mm}$.

The standardized procedure for sample preparation is illustrated in Figure 3. To prepare the sample, solid materials (see Table 3) were added to the stirring tank and mixed at a constant speed for $5 \mathrm{~min}$ and then deionized water was added to the solid materials and they were mixed again for $5 \mathrm{~min}$. Afterward, the formed mixture was filled into a mold in three layers, and each layer was statically compacted for 2 min using the YAW-300 press machine produced by Jinan Zhongluchang Testing Machine Manufacturing Company (Figure 4(a)). Subsequently, the sample together with the mold was placed into a curing box at a temperature of $20 \pm 3^{\circ} \mathrm{C}$ and a humidity of $95 \%$ for $24 \mathrm{~h}$. After demolding, the sample was continuously cured for $28 \mathrm{~d}$. Finally, the samples with smooth surfaces and without obvious defects were selected. 
TABLE 5: Secondary refinement test scheme of similar materials.

\begin{tabular}{lcccc}
\hline \multirow{2}{*}{ Scheme } & A (water content \%) & B (barite powder ratio \%) & C (gypsum mass g) & D (clay mineral ratio \%) \\
\hline S1 & 19 & 32 & 250 & 0 \\
S2 & 19 & 32 & 250 & 6 \\
S3 & 19 & 32 & 250 & 12 \\
S4 & 19 & 32 & 250 & 18 \\
\hline
\end{tabular}

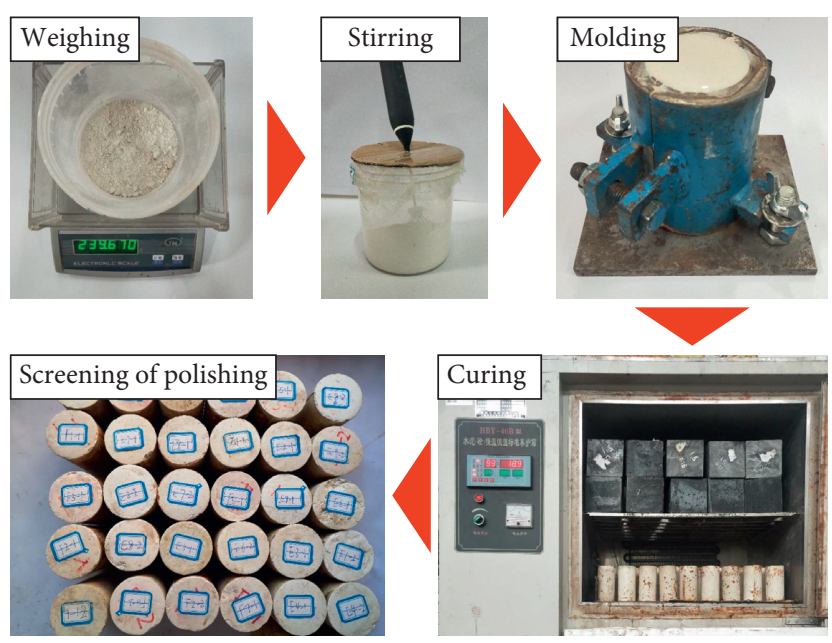

FIgURE 3: Sample preparation process.

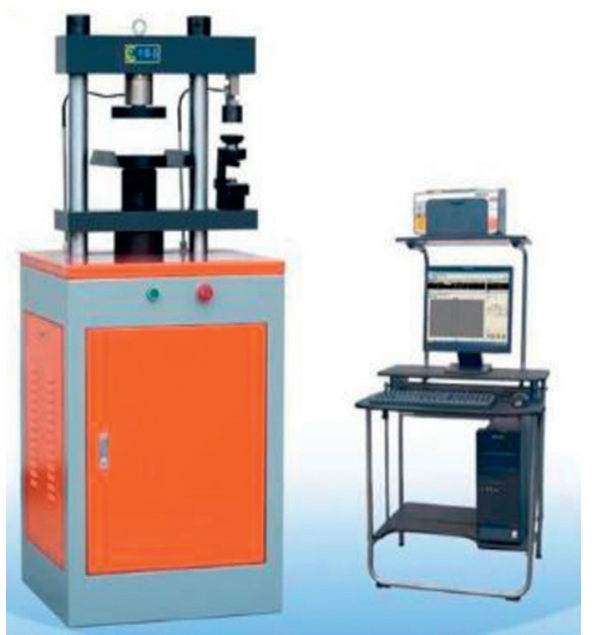

(a)
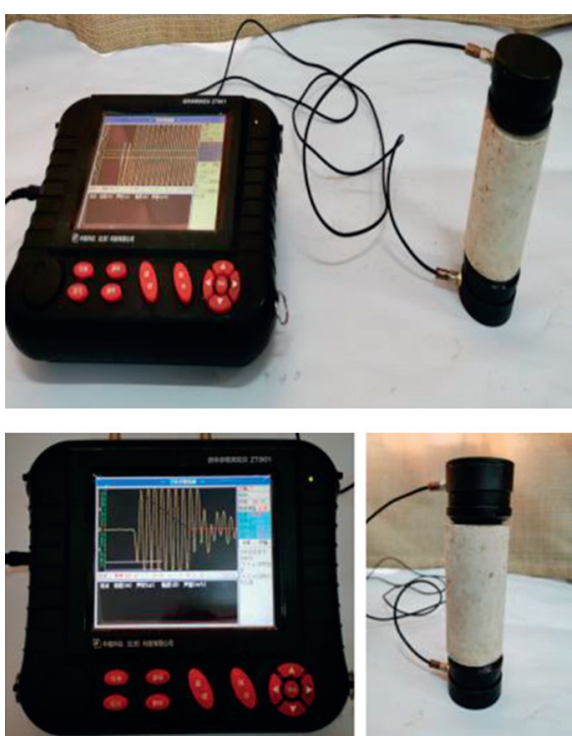

(b)

Figure 4: Continued. 

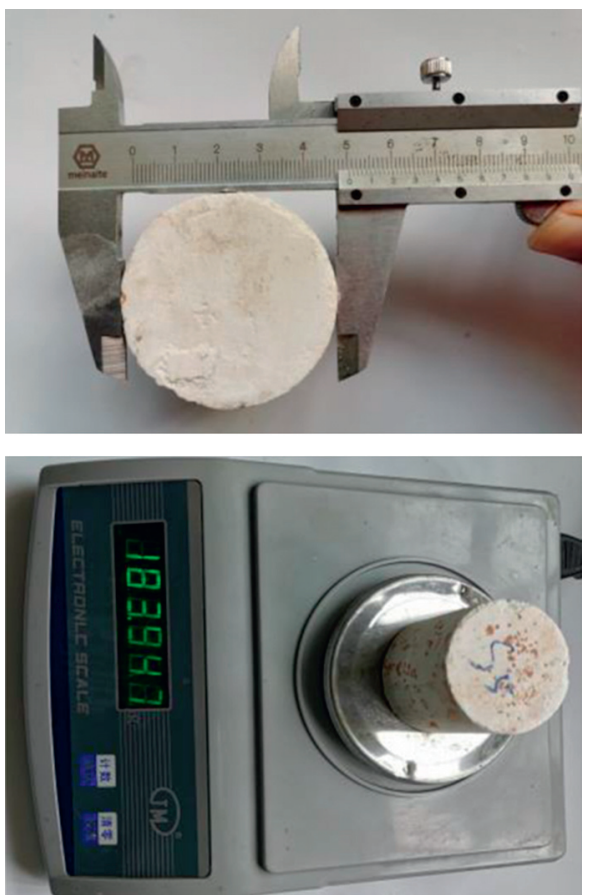

(c)

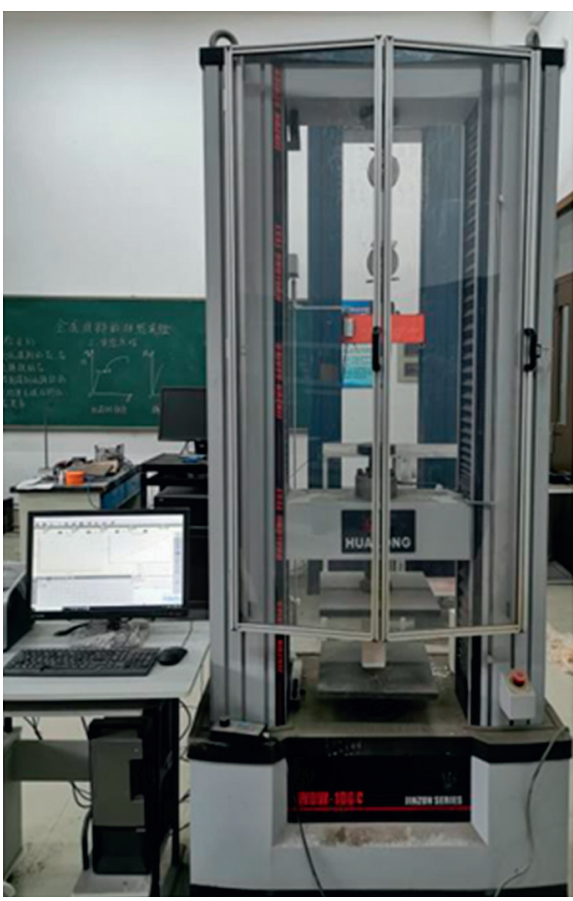

(d)

Figure 4: Testing equipment: (a) YAW-300 press machine; (b) ZT801 ultrasonic wave velocity tester; (c) vernier caliper and electronic balance; (d) universal pressure testing machine.

3.2. Sample Screening. In the process of making similar materials, some defects may exist in the samples because of nonuniform stirring, big air bubbles, and other uncontrollable factors. In particular, internal defects cannot be discerned by the naked eye. The existence of defects that vary from sample to sample will definitely bring about errors to the experimental results. According to the existing research, the physical properties of the rock itself can affect the propagation speed of ultrasonic waves in rocks [3, 37]. Therefore, the physical and mechanical properties of rock can be inferred indirectly by measuring the velocity of ultrasonic wave in rock mass [38-40].

In the current study, the velocities of ultrasonic waves in all similar material samples were detected by the rock mass parameter tester ZT801 (Figure 4(b)). The specific test results are presented in Table 6 . It shows that the ultrasonic wave velocities of the similar materials fall between $2.84 \mathrm{~km} / \mathrm{s}$ and $3.25 \mathrm{~km} / \mathrm{s}$. The samples in each scheme have very close ultrasonic wave velocities, which ensure that these samples have similar initial conditions.

\subsection{Experimental Methods}

3.3.1. Physical and Mechanical Tests. The density, uniaxial compressive strength, tensile strength, elastic modulus, and Poisson's ratio of the samples were measured using the samples prepared according to the orthogonal design table (Table 4).

The density of each sample was measured before mechanical tests. As shown in Figure 4(c), the volume of each sample was determined by a vernier caliper with precision of $0.02 \mathrm{~mm}$, while the mass was weighed using an electronic balance with precision of $0.01 \mathrm{~g}$.

Uniaxial compression tests and splitting tests were conducted via a universal pressure testing machine (see Figure 4(d)). Cylindrical samples for uniaxial compression tests had diameters of $50 \mathrm{~mm}$ and heights of $50 \mathrm{~mm}[36,41]$. The maximum load and the accuracy of the testing machine are $100 \mathrm{kN}$ and $0.001 \mathrm{~N}$, respectively. The whole test process is in accordance with the Chinese specification (GB/T 502662013). The loading rates were $0.8 \mathrm{MPa} / \mathrm{s}$ and $0.4 \mathrm{MPa} / \mathrm{s}$ for uniaxial compression tests and splitting tests, respectively.

According to the method recommended by GB/T 502662013 [42], the elastic modulus can be estimated based on the slope of the stress-strain curve obtained by uniaxial compression tests. Poisson's ratio was measured via the resistance strain gauge method $[43,44]$. In this method, the ratio of transverse strain increment to longitudinal strain increment was measured, and thus Poisson's ratio of each sample could be calculated.

3.3.2. Water-Absorption Tests and Expansibility Tests. The water absorption and saturated water absorption of the rock and similar materials were measured by free waterabsorption tests $[42,45]$. Five raw rock samples or similar material samples were used for each test scheme. The main testing procedures were as follows:

(1) The sample was put in the oven at a temperature of $105^{\circ} \mathrm{C}-110^{\circ} \mathrm{C}$. After drying for $12-24 \mathrm{~h}$, the sample 
TABLE 6: Ultrasonic wave velocities of similar material samples.

\begin{tabular}{|c|c|c|c|c|c|c|}
\hline Scheme & Sample $1(\mathrm{~km} / \mathrm{s}$ & Sample $2(\mathrm{~km} / \mathrm{s})$ & Sample $3(\mathrm{~km} / \mathrm{s})$ & Sample $4(\mathrm{~km} / \mathrm{s})$ & Sample $5(\mathrm{~km} / \mathrm{s})$ & Difference $(\mathrm{km} / \mathrm{s})$ \\
\hline 1 & 2.98 & 2.99 & 3.00 & 2.99 & 2.99 & 0.01 \\
\hline 2 & 2.91 & 2.90 & 2.98 & 3.06 & 3.01 & 0.16 \\
\hline 3 & 2.96 & 2.94 & 3.02 & 3.05 & 3.10 & 0.16 \\
\hline 4 & 2.94 & 2.95 & 2.97 & 2.96 & 2.96 & 0.03 \\
\hline 5 & 2.92 & 2.95 & 3.01 & 3.05 & 3.02 & 0.12 \\
\hline 6 & 3.15 & 3.14 & 3.25 & 3.18 & 3.21 & 0.12 \\
\hline 7 & 2.99 & 2.97 & 3.01 & 3.01 & 3.04 & 0.07 \\
\hline 8 & 2.86 & 2.84 & 2.90 & 2.96 & 2.90 & 0.12 \\
\hline 9 & 3.10 & 3.12 & 3.08 & 3.00 & 3.13 & 0.13 \\
\hline 10 & 2.97 & 2.94 & 2.91 & 2.91 & 2.90 & 0.06 \\
\hline 11 & 3.05 & 3.07 & 2.99 & 2.99 & 3.01 & 0.08 \\
\hline 12 & 3.08 & 3.09 & 3.03 & 3.05 & 3.00 & 0.10 \\
\hline 13 & 3.00 & 2.99 & 2.97 & 3.00 & 2.99 & 0.03 \\
\hline 14 & 2.97 & 2.99 & 2.98 & 2.99 & 2.99 & 0.02 \\
\hline 15 & 3.00 & 3.01 & 3.06 & 3.09 & 3.01 & 0.09 \\
\hline 16 & 2.97 & 2.98 & 2.98 & 2.98 & 2.95 & 0.04 \\
\hline
\end{tabular}

was taken out and cooled down to the room temperature $\left(20^{\circ} \mathrm{C} \pm 2^{\circ} \mathrm{C}\right)$. The mass $\left(m_{d}\right)$ of the sample is then recorded (accuracy: $0.01 \mathrm{~g}$ ).

(2) Determination of the natural water absorption: first, the dried sample was placed in a water container. Then, water was filled to $1 / 4$ of the height of the sample. Two hours later, water was filled into the container to reach a level between $1 / 2$ and $3 / 4$ of the height of the sample. After $6 \mathrm{~h}$, water was continuously added to a height of $20 \mathrm{~mm}$ above the top surface of the sample. In this way, the air in the sample could escape easily. After $48 \mathrm{~h}$ immersion in water, the sample was taken out, and the surface water was wiped off with a piece of wet gauze. The sample mass $\left(m_{1}\right)$ was measured again. Thus, the water absorption can be calculated by

$$
w_{a}=\frac{m_{1}-m_{d}}{m_{d}} \times 100,
$$

where $w_{a}$ is the water absorption of the sample.

(3) Determination of the saturated water absorption: the dried sample was placed in a vacuum container, and the water level inside the container was $20 \mathrm{~mm}$ higher than the top surface of the sample. Then, a vacuum pump was started to evacuate the container. The vacuum pressure should reach and remain at $100 \mathrm{kPa}$ for not less than $4 \mathrm{~h}$. Afterward, the specimen was remained in the container for $4 \mathrm{~h}$ at the atmosphere pressure. Then the specimen was taken out and dried with a piece of wet gauze. Finally, the mass $\left(m_{2}\right)$ of the sample was measured. The water absorption can be calculated by the following expression:

$$
w_{\text {sat }}=\frac{m_{2}-m_{d}}{m_{d}} \times 100
$$

where $w_{\text {sat }}$ is the saturated water absorption of the sample.
Free water-expansion tests were also conducted in order to evaluate the water-expansion characteristic of similar materials and the raw rock (JTG E41-2005). Five samples were used for each test scheme in Table 5. The free expansion rate of the material was defined as

$$
P_{H}=\frac{\Delta H}{H} \times 100 \text {, }
$$

where $P_{H}$ is the axial free expansion rate; $\Delta H$ is the axial deformation of the sample; $H$ is the initial axial height of the sample.

3.3.3. SEM Observations. Scanning electron microscopy (SEM) observations were performed to examine the microstructure of similar materials and further confirm the similarity in water-absorption and water-expansion properties, since they are highly dependent on pore structures. SEM observations were conducted on the horizontal and vertical planes on the small specimens extracted from the cylindrical samples for secondary refinement tests (Table 5). Two cuboids with dimensions of $20 \mathrm{~mm} \times 10 \mathrm{~mm} \times 10 \mathrm{~mm}$ were extracted from the core of each sample [37, 46]. The longitudinal directions of the cuboids were parallel or perpendicular to the axial direction of the cylindrical sample. This method for small-sample extractions is similar to that presented in the work of Gao et al. [46, 47]. Before SEM observations, the observation planes of the sample were coated with thin layers of gold under vacuum. The purpose was to make the plane electrically conductive in order to prevent any charge build-up on the sample. Thereafter, the sample was placed in the chamber of a scanning electron microscope (ZEISS EVO MA10) for observation. A series of SEM images with different magnifications were saved from typical areas in the observation plane of each sample. Finally, the surface morphology (e.g., pore sizes and porosity) of the sample was analyzed following the method described in the work of Gao et al. [48]. 


\section{Results and Discussion}

4.1. Mixing Ratios for Similarity in Physical and Mechanical Properties. In this section, the influences of various factors (i.e., A, water content; B, barite powder ratio; C, gypsum mass; and D, clay mineral ratio) on the physical and mechanical properties (i.e., the density, uniaxial compressive strength, tensile strength, elastic modulus, and Poisson's ratio) of similar materials are examined. Then, the optimal mixing ratios for similar materials to have similar physical and mechanical behaviors to those of the raw silty mudstone are determined. In addition, typical stress-strain curves and failure modes of similar materials and the raw rock after uniaxial compression tests are compared and discussed.

4.1.1. Results of Physical and Mechanical Tests. Table 7 summarizes the mean results of parallel samples in each test scheme arranged according to the orthogonal design. It shows that the density of the prepared similar materials varies from 1.82 to $2.08 \mathrm{~g} / \mathrm{cm}^{3}$, the range of uniaxial compressive strength is between 8.28 and 18.19 MPa, and the tensile strength falls between 1.01 and 4.00 MPa. It is also observed that the elastic modulus changes from 1.01 to $2.38 \mathrm{GPa}$, and Poisson's ratio ranges from 0.20 to 0.40 . Comparing the results in Table 7 with those in Table 3, one can note that the properties (target values) of silty mudstone are covered by the data of similar materials. This confirms that the physical and mechanical behaviors of silty mudstone can be simulated with similar materials.

4.1.2. Sensitivity Analysis. Range analysis and variance analysis are conducted to investigate the sensitivity of physical and mechanical properties to various factors.

(1) Sensitivity analysis of factors affecting rock density: As can be seen from Table 8 and Figure 5, factor A (water content) and factor $\mathrm{C}$ (gypsum mass) have the greatest influence on the density of similar materials. According to the rank, the influence degree of each factor on the density of similar materials is $A \approx C>B \approx D$. Thus, the main controlling factors that influence the density of similar materials are factor A (water content) and factor C (gypsum mass).

The results of variance analysis of the density are shown in Table 8. Under the condition of a confidence level of 0.1 , the critical value of significance is 5.390. It is observed that factors A (water content) and C (gypsum mass) had significant influences on the density of similar materials, while factors B (barite powder ratio) and D (clay mineral ratio) showed fewer influences. This is consistent with the result of range analysis (Table 9).

As shown in Table 3, the average density of the raw rock is $2.01 \mathrm{~g} / \mathrm{cm}^{3}$. This target value is between the results of similar materials when the evaluation index is $K_{2}$ and $K_{3}$ regarding factor $A$, and it equals the result when the evaluation index is $K_{2}$ regarding factor $\mathrm{C}$ (Table 8). Thus, the suitable factor A (water content) is $19 \%$ (level 2) and $21 \%$ (level 3), and the optimal factor C (gypsum mass) is $250 \mathrm{~g}$ (level 2) in order to bring such a target physical property to similar materials.

(2) Sensitivity analysis of factors affecting uniaxial compressive strength: Table 10 and Figure 6 show that factor $C$ (gypsum mass) has the highest influence and factor D (clay mineral ratio) has the second highest influence on the uniaxial compressive strength of similar materials. According to the rank, the influence degree of each factor on the uniaxial compressive strength of similar materials is $C \approx D>A \approx B$. The analysis indicates that factors $C$ (gypsum mass) and $D$ (clay mineral ratio) play a leading role in controlling the uniaxial compressive strength of similar material samples.

Table 11 shows the results of variance analysis of the uniaxial compressive strength of similar materials. One can note that, as far as uniaxial compressive strength is concerned, the influences of those examined factors on uniaxial compressive strength are all not so significant.

(3) Sensitivity analysis of factors affecting tensile strength: Table 12 and Figure 7 present the results of range analysis of the tensile strength of similar materials. It is noted that factor A (water content) has the greatest influence on the tensile strength of similar materials. According to the influence degree of each factor on the tensile strength, the factors are ranked as $A>B>D>C$. The analysis shows that factor A (water content) and factor B (barite powder ratio) play a dominant role in controlling the tensile strength of similar material samples.

Table 13 lists the results of variance analysis of the tensile strength of similar materials. One can note that factor A (water content) and factor B (barite powder ratio) have significant influence on the tensile strength, while the other factors show limited influences. This is also in agreement with the result of range analysis (Table 12).

(4) Sensitivity analysis of factors affecting elastic modulus. It is observed from Table 14 and Figure 8 that factor A (water content) has the most significant influence on the elastic modulus of similar materials. According to the rank, the influence degree of each factor on the elastic modulus of similar material samples is $A>D \approx B>C$. The analysis shows that factor $A$ (water content) plays a dominant role in controlling the elastic modulus of similar material samples. The relationship between other factors and the elastic modulus of the sample is not very obvious.

Furthermore, according to the results of variance analysis (Table 15), it is noted that factor A (water content) has a significant influence on the tensile strength, while other factors do not show significant influences, which confirms the results of range analysis.

As shown in Table 3, the average elastic modulus of the raw rock is $1.38 \mathrm{GPa}$. Combined with Table 15 and Table 4, one can conclude that the optimal water content is $19 \%$ in order to prepare a similar material that has similar elastic modulus as the raw silty mudstone.

(5) Sensitivity analysis of factors affecting Poisson's ratio: Based on the results shown in Table 16 and Figure 9, one can rank the examined factors as $A \approx D \approx B \approx C$ according to the degree of their influences on Poisson's ratio of similar 
TABLe 7: Physical and mechanical properties of similar materials.

\begin{tabular}{|c|c|c|c|c|c|}
\hline Scheme & Density $\rho\left(\mathrm{g} / \mathrm{cm}^{3}\right)$ & $\begin{array}{l}\text { Uniaxial compressive strength } \sigma_{\mathrm{c}} \\
(\mathrm{MPa})\end{array}$ & $\begin{array}{l}\text { Tensile strength } \sigma_{\mathrm{t}} \\
(\mathrm{MPa})\end{array}$ & Elastic modulus $E(\mathrm{GPa})$ & Poisson's ratio $v$ \\
\hline 1 & 1.95 & 13.54 & 2.94 & 1.74 & 0.28 \\
\hline 2 & 1.91 & 11.91 & 3.33 & 1.61 & 0.23 \\
\hline 3 & 1.84 & 10.74 & 2.72 & 1.40 & 0.27 \\
\hline 4 & 1.82 & 11.65 & 4.00 & 1.35 & 0.25 \\
\hline 5 & 2.05 & 10.22 & 1.99 & 1.64 & 0.40 \\
\hline 6 & 2.08 & 18.19 & 2.08 & 2.38 & 0.20 \\
\hline 7 & 1.97 & 9.01 & 1.47 & 1.60 & 0.27 \\
\hline 8 & 1.89 & 12.74 & 2.89 & 1.81 & 0.38 \\
\hline 9 & 2.08 & 8.28 & 1.01 & 1.07 & 0.21 \\
\hline 10 & 1.92 & 9.24 & 1.70 & 1.38 & 0.22 \\
\hline 11 & 2.05 & 14.18 & 1.61 & 1.33 & 0.23 \\
\hline 12 & 2.05 & 12.24 & 2.84 & 1.29 & 0.21 \\
\hline 13 & 2.01 & 13.69 & 3.73 & 1.96 & 0.38 \\
\hline 14 & 1.99 & 13.09 & 3.92 & 1.34 & 0.31 \\
\hline 15 & 2.02 & 13.58 & 3.05 & 1.33 & 0.22 \\
\hline 16 & 2.08 & 10.47 & 3.81 & 1.01 & 0.21 \\
\hline
\end{tabular}

TABLE 8: Range analysis of rock density.

\begin{tabular}{lcccc}
\hline \multirow{2}{*}{ Evaluation indexes } & \multicolumn{4}{c}{$\begin{array}{c}\text { Density }\left(\mathrm{g} / \mathrm{cm}^{3} \text { ) }\right. \\
\end{array}$} \\
\cline { 2 - 5 } & Factor A (water content) & Factor B (barite powder ratio) & Factor C (gypsum mass) & Factor D (clay mineral ratio) \\
\hline$K_{1}$ & 1.88 & 2.02 & 2.04 & 1.99 \\
$K_{2}$ & 2.00 & 1.98 & 2.01 & 1.97 \\
$K_{3}$ & 2.03 & 1.97 & 1.95 & 1.97 \\
$K_{4}$ & 2.03 & 1.96 & 1.93 & 2.00 \\
Range value $R$ & 0.15 & 0.06 & 0.11 & 0.04 \\
Rank & 1 & 3 & 2 & 4 \\
\hline
\end{tabular}

Note. $K_{i}(i=1,2,3,4)$ represents the mean of the density values corresponding to level $i$ of a factor; $R=\max \left(K_{i}\right)-\min \left(K_{i}\right)(i=1,2,3$, and 4$)$.

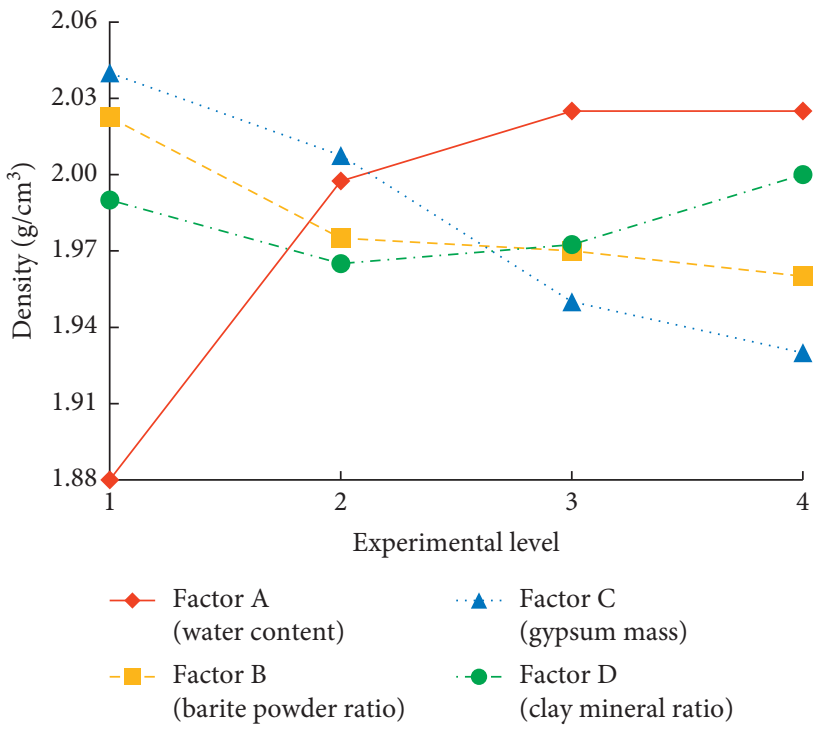

FIGURE 5: Range analysis of the factors affecting density.

material samples. Therefore, Poisson's ratio is hard to judge by factors A-D.

The results of variance analysis shown in Table 17 indicate that, regarding Poisson's ratio, the influences of all factors are not significant. This is consistent with the results of range analysis.
Based on the above sensitivity analyses, the optimal mixing ratios of similar materials that show good similarity to those of the raw silty mudstone in terms of the physical and mechanical properties are determined. The optimal water content is $19 \%$, the optimal barite powder ratio is $32 \%$, and the optimal gypsum mass is $250 \mathrm{~g}$. However, factor D (clay mineral ratio) is still not determined because it has no clear contribution to the above physical and mechanical properties of similar materials.

\subsubsection{Typical Stress-Strain Curves and Failure} Characteristics. Figure 10(a) presents typical stress-strain curves of similar materials and silty mudstone obtained from uniaxial compression tests. Figure 10(b) illustrates the corresponding failure modes of the samples.

A comparative analysis of the failure modes of similar material samples and the raw rock is conducted. The silty mudstone sample shows an obvious shear failure after uniaxial compression tests, which is in line with the results reported [49]. It is also noted that the shear failure modes of similar material samples are quite similar to those of the raw rock under uniaxial compression tests (Figure 10).

4.2. Mixing Ratios for Similarity in Water Absorption and Expansion. In this section, the influence of factor D (clay mineral ratio) on the water-absorption and water-expansion 
TABLE 9: Variance analysis of density.

\begin{tabular}{|c|c|c|c|c|c|}
\hline Factor & A (water content) & B (barite powder ratio) & C (gypsum mass) & $\mathrm{D}$ (clay mineral ratio) & Error \\
\hline Variance value $S^{2}$ & 0.057 & 0.009 & 0.031 & 0.003 & 0 \\
\hline Degrees of freedom $F$ & 3 & 3 & 3 & 3 & 3 \\
\hline Univariate significance & $\begin{array}{c}19.000 \\
\text { Significant }\end{array}$ & $\begin{array}{c}3.000 \\
\text { Insignificant }\end{array}$ & $\begin{array}{c}10.333 \\
\text { Significant }\end{array}$ & $\begin{array}{c}1.000 \\
\text { Insignificant }\end{array}$ & \\
\hline
\end{tabular}

Note. $S^{2}$ represents the mean of the density variance value corresponding to level $i$ of a factor; $S^{2}=\sum_{i=1}^{4}\left(K_{i}-(1 / 4) \sum_{i=1}^{4} K_{i}\right)^{2} / 5$.

TABLE 10: Range analysis of uniaxial compressive strength.

\begin{tabular}{lcccc}
\hline \multirow{2}{*}{ Evaluation indexes } & \multicolumn{4}{c}{ Uniaxial compressive strength (MPa) } \\
& Factor A (water content) & Factor B (barite powder ratio) & Factor C (gypsum mass) & Factor D (clay mineral ratio) \\
\hline$K_{1}$ & 11.96 & 11.43 & 14.10 & 11.97 \\
$K_{2}$ & 12.54 & 13.11 & 11.99 & 13.13 \\
$K_{3}$ & 10.99 & 11.88 & 11.21 & 10.17 \\
$K_{4}$ & 14.71 & 11.78 & 10.90 & 13.13 \\
Range value $R$ & 1.72 & 1.68 & 3.20 & 2.96 \\
Rank & 3 & 4 & 1 & 2 \\
\hline
\end{tabular}

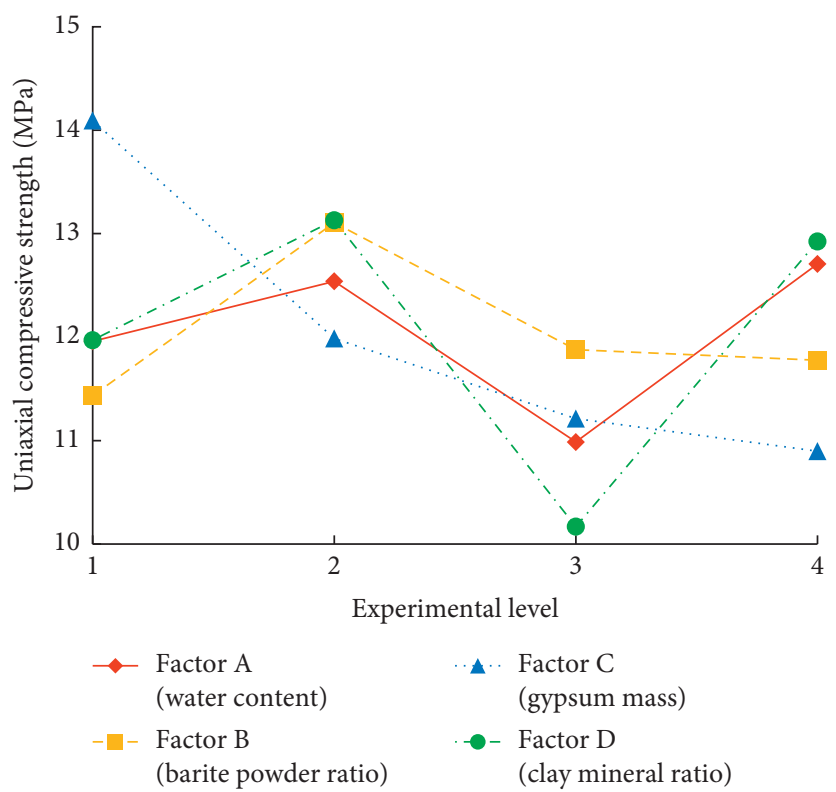

FIgURE 6: Range analysis of the factors affecting uniaxial compressive strength.

TABLE 11: Variance analysis of uniaxial compressive strength.

\begin{tabular}{|c|c|c|c|c|c|}
\hline Factor & A (water content) & B (barite powder ratio) & C (gypsum mass) & D (clay mineral ratio) & Error \\
\hline Variance value $S^{2}$ & 7.259 & 6.420 & 24.862 & 21.929 & 222.47 \\
\hline Degrees of freedom $F$ & 3 & 3 & 3 & 3 & 3 \\
\hline Univariate significance & $\begin{array}{c}0.033 \\
\text { Insignificant }\end{array}$ & $\begin{array}{c}0.029 \\
\text { Insignificant }\end{array}$ & $\begin{array}{c}0.112 \\
\text { Insignificant }\end{array}$ & $\begin{array}{c}0.099 \\
\text { Insignificant }\end{array}$ & \\
\hline
\end{tabular}

characteristics of similar materials is analyzed. Most importantly, the optimal level of factor D (clay mineral ratio) is determined.

As shown in Figure 11, the average natural water absorption of the raw silty mudstone is $10.85 \%$, and the average saturated water absorption is $11.83 \%$. According to the secondary refinement test scheme, the average natural water absorption rates of similar material samples in schemes S1-S4 with different clay mineral ratios are $8.41 \%$, $9.82 \%, 10.86 \%$, and $11.52 \%$, respectively. The average saturated water absorption is $9.89 \%, 10.85 \%, 11.84 \%$, and $12.33 \%$, respectively. Moreover, the average natural water absorption and saturated water absorption of similar material samples increase with the increase of clay mineral 
TABLE 12: Range analysis of tensile strength.

\begin{tabular}{lcccc}
\hline Evaluation indexes & \multicolumn{2}{c}{ Tensile strength (MPa) } \\
& Factor A (water content) & $\begin{array}{c}\text { Factor B (barite powder } \\
\text { ratio) }\end{array}$ & $\begin{array}{c}\text { Factor C (gypsum } \\
\text { mass) }\end{array}$ & $\begin{array}{c}\text { Factor D (clay mineral } \\
\text { ratio) }\end{array}$ \\
\hline$K_{1}$ & 3.25 & 2.42 & 2.61 & 2.79 \\
$K_{2}$ & 2.11 & 2.76 & 2.81 & 2.89 \\
$K_{3}$ & 1.79 & 2.21 & 2.64 & 2.56 \\
$K_{4}$ & 3.63 & 3.39 & 2.73 & 2.54 \\
Range value $R$ & 1.84 & 1.17 & 0.19 & 0.36 \\
Rank & 1 & 2 & 4 & 3 \\
\hline
\end{tabular}

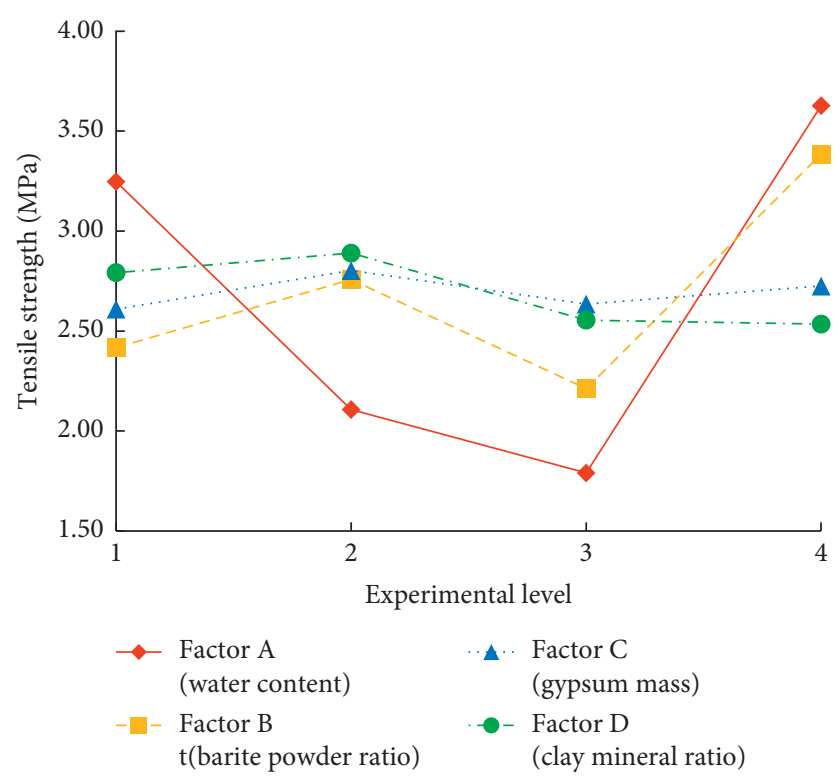

FIGURE 7: Range analysis of the factors affecting tensile strength.

TABLE 13: Variance analysis of tensile strength.

\begin{tabular}{|c|c|c|c|c|c|}
\hline Factor & A (water content) & B (barite powder ratio) & C (gypsum mass) & $\mathrm{D}$ (clay mineral ratio) & Error \\
\hline Variance value $S^{2}$ & 9.356 & 3.159 & 0.093 & 0.371 & 0.090 \\
\hline Degrees of freedom $F$ & 3 & 3 & 3 & 3 & 3 \\
\hline Univariate significance & $\begin{array}{c}100.602 \\
\text { Significant }\end{array}$ & $\begin{array}{c}33.968 \\
\text { Significant }\end{array}$ & $\begin{array}{c}1.000 \\
\text { Insignificant }\end{array}$ & $\begin{array}{c}3.989 \\
\text { Insignificant }\end{array}$ & \\
\hline
\end{tabular}

TABLE 14: Range analysis of elastic modulus.

\begin{tabular}{lcccc}
\hline \multirow{2}{*}{ Evaluation indexes } & \multicolumn{3}{c}{ Elastic modulus (GPa) } \\
& Factor A (water content) & Factor B (barite powder ratio) & Factor C (gypsum mass) & Factor D (clay mineral ratio) \\
\hline$K_{1}$ & 1.53 & 1.60 & 1.62 & 1.49 \\
$K_{2}$ & 1.86 & 1.68 & 1.48 & 1.68 \\
$K_{3}$ & 1.27 & 1.42 & 1.41 & 1.36 \\
$K_{4}$ & 1.41 & 1.37 & 1.57 & 1.53 \\
Range value $R$ & 0.59 & 0.31 & 0.21 & 0.32 \\
Rank & 1 & 3 & 4 & 2 \\
\hline
\end{tabular}

ratio. Therefore, the change of clay mineral ratio enables controlling the water absorption of similar materials. Based on the test data, one can note that the average water absorption of the similar material samples in the third test scheme S3 is the closest to the average value of the raw rock (the error is less than 1\%).
Figure 12 shows that the variation curve of free expansion rates of similar material samples and silty mudstone can be divided into three stages. The first is the rapid expansion stage $(t<2 \mathrm{~h})$, during which the average axial expansion rates of similar material samples with different clay mineral ratios and raw rocks increase rapidly to the final 


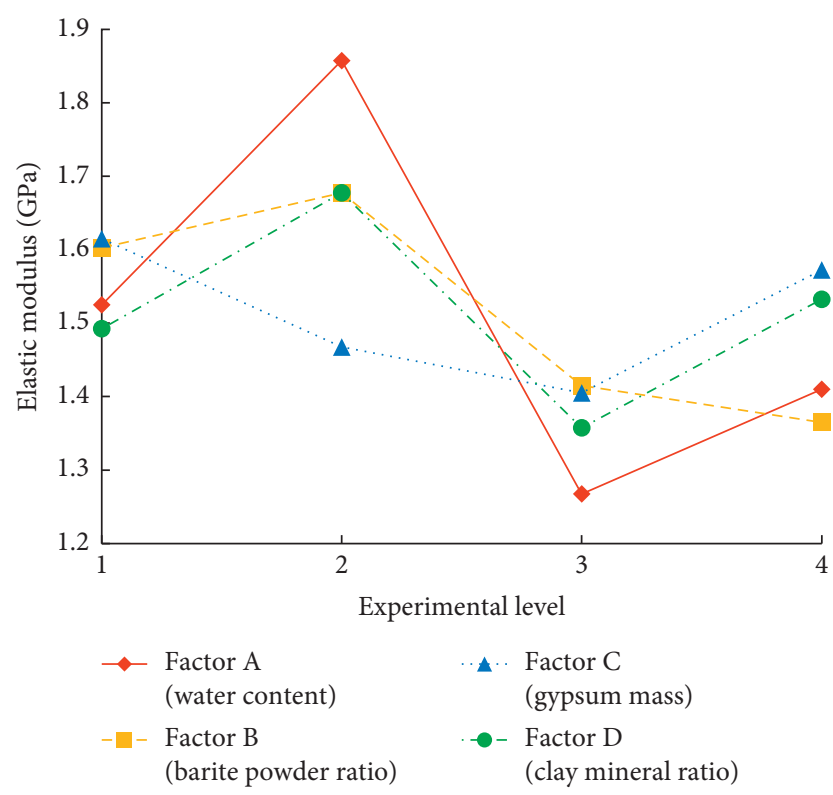

Figure 8: Range analysis of the factors affecting elastic modulus.

TABLE 15: Variance analysis of elastic modulus.

\begin{tabular}{|c|c|c|c|c|c|}
\hline Factor & A (water content) & B (barite powder ratio) & $\mathrm{C}$ (gypsum mass) & $\mathrm{D}$ (clay mineral ratio) & Error \\
\hline$S^{2}$ & 0.759 & 0.266 & 0.111 & 0.208 & 0.110 \\
\hline Degrees of freedom $F$ & 3 & 3 & 3 & 3 & 3 \\
\hline Univariate significance & $\begin{array}{c}6.838 \\
\text { Significant }\end{array}$ & $\begin{array}{c}2.396 \\
\text { Insignificant }\end{array}$ & $\begin{array}{c}1.000 \\
\text { Insignificant }\end{array}$ & $\begin{array}{c}1.874 \\
\text { Insignificant }\end{array}$ & \\
\hline
\end{tabular}

TABLE 16: Range analysis of Poisson's ratio.

\begin{tabular}{lcccc}
\hline \multirow{2}{*}{ Evaluation indexes } & \multicolumn{4}{c}{$\begin{array}{c}\text { Poisson's ratio } \\
\end{array}$} \\
\cline { 2 - 5 } & Factor A (water content) & Factor B (barite powder ratio) & Factor C (gypsum mass) & Factor D (clay mineral ratio) \\
\hline$K_{1}$ & 0.26 & 0.32 & 0.23 & 0.27 \\
$K_{2}$ & 0.31 & 0.24 & 0.27 & 0.31 \\
$K_{3}$ & 0.22 & 0.25 & 0.29 & 0.28 \\
$K_{4}$ & 0.28 & 0.26 & 0.28 & 0.22 \\
Range value $R$ & 0.10 & 0.08 & 0.06 & 0.09 \\
Rank & 1 & 3 & 4 & 2 \\
\hline
\end{tabular}

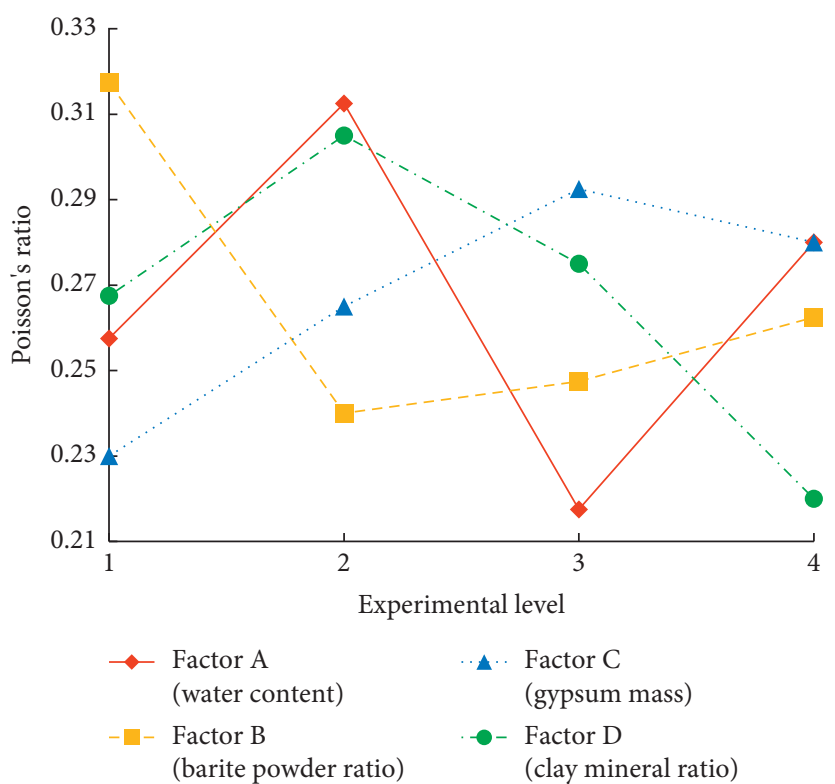

Figure 9: Range analysis of the factors affecting Poisson's ratio. 
Table 17: Variance analysis of Poisson's ratio.

\begin{tabular}{|c|c|c|c|c|c|}
\hline Factor & A (water content) & B (barite powder ratio) & $\mathrm{C}$ (gypsum mass) & $\mathrm{D}$ (clay mineral ratio) & Error \\
\hline Variance value $S^{2}$ & 0.019 & 0.015 & 0.009 & 0.015 & 0.010 \\
\hline Degrees of freedom $F$ & 3 & 3 & 3 & 3 & 3 \\
\hline Univariate significance & $\begin{array}{c}2.111 \\
\text { Insignificant }\end{array}$ & $\begin{array}{c}1.667 \\
\text { Insignificant }\end{array}$ & $\begin{array}{c}1.000 \\
\text { Insignificant }\end{array}$ & $\begin{array}{c}1.667 \\
\text { Insignificant }\end{array}$ & \\
\hline
\end{tabular}

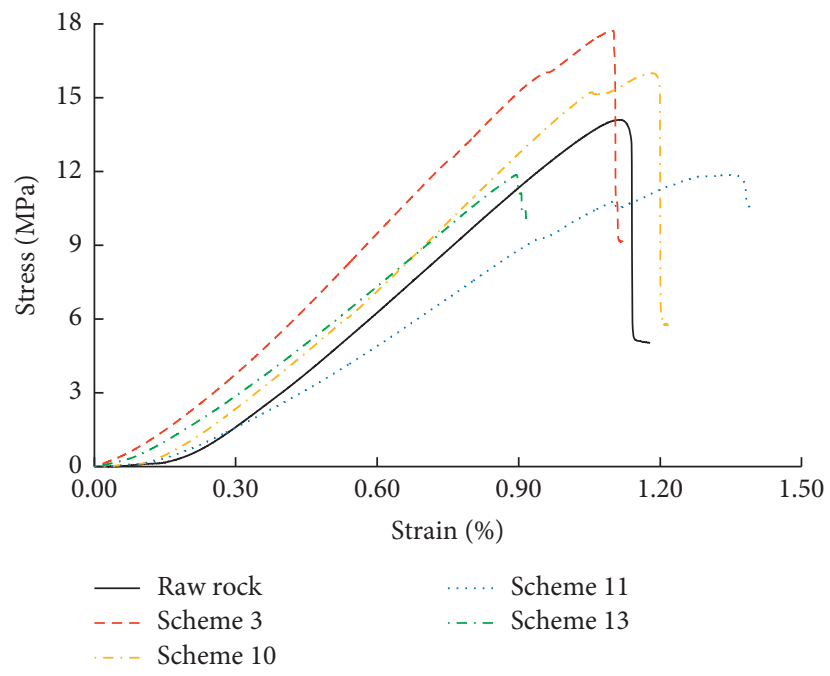

(a)

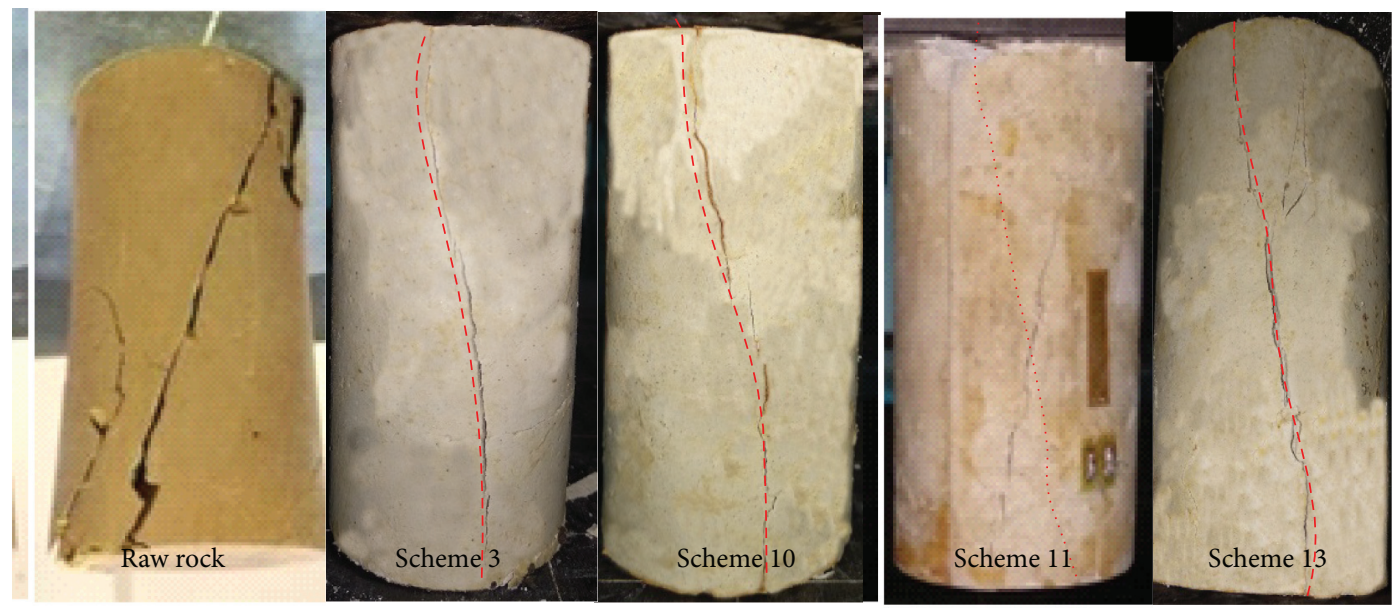

(b)

Figure 10: Typical stress-strain curve and failure modes diagram: (a) stress-strain curves; (b) failure modes.

average axial expansion rates of $0.1154 \%, 0.1238 \%, 0.1342 \%$, $0.1966 \%$, and $0.1369 \%$, respectively. Later, the expansion rates of all samples enter the constant expansion stage $(t=2-15 \mathrm{~h})$. In this stage, the similar material samples S1 S4 and the raw rock show a constant linear growth rate of $11.54 \times 10^{-5} / \mathrm{min}, \quad 12.38 \times 10^{-5} / \mathrm{min}, \quad 13.42 \times 10^{-5} / \mathrm{min}$, $19.66 \times 10^{-5} / \mathrm{min}$, and $13.86 \times 10^{-5} / \mathrm{min}$, respectively. Afterward, the expansion rate of all samples enters the deceleration stage $(t=15-120 \mathrm{~h})$, and the expansion rate is gradually stabilized. This period takes a long time, accounting for $87.5 \%$ of the total expansion stage. It can be seen that similar materials have similar water absorption and expansibility with the raw rock. The expansion rates of samples S1-S4 are all within the range of the raw rock, and the expansion rates gradually increase with the increase of clay mineral ratio. Among them, the curves of the axial expansion rates of sample S3 (whose clay mineral ratio is $12 \%)$ are the closest to the average value of the raw rock.

Table 18 summarizes the mean physical parameters of the similar material samples prepared at optimal water content (19\%), barite powder ratio (32\%), and gypsum mass ( $250 \mathrm{~g})$ but different clay mineral ratios $(0-18 \%)$. The data of raw rock samples are also included for comparison purposes. One can note that the similar material samples in test 


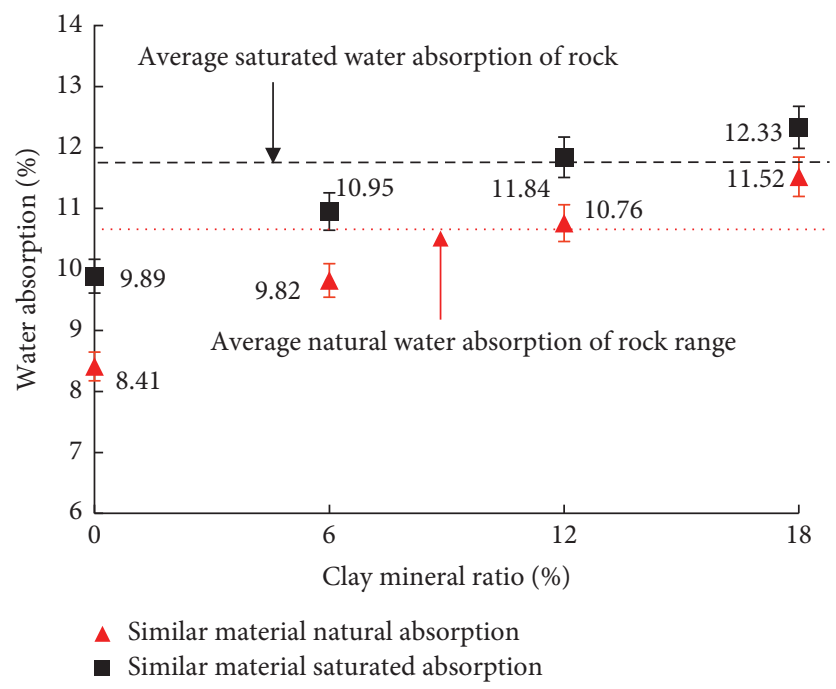

FiguRE 11: Water absorption and saturated water absorption.

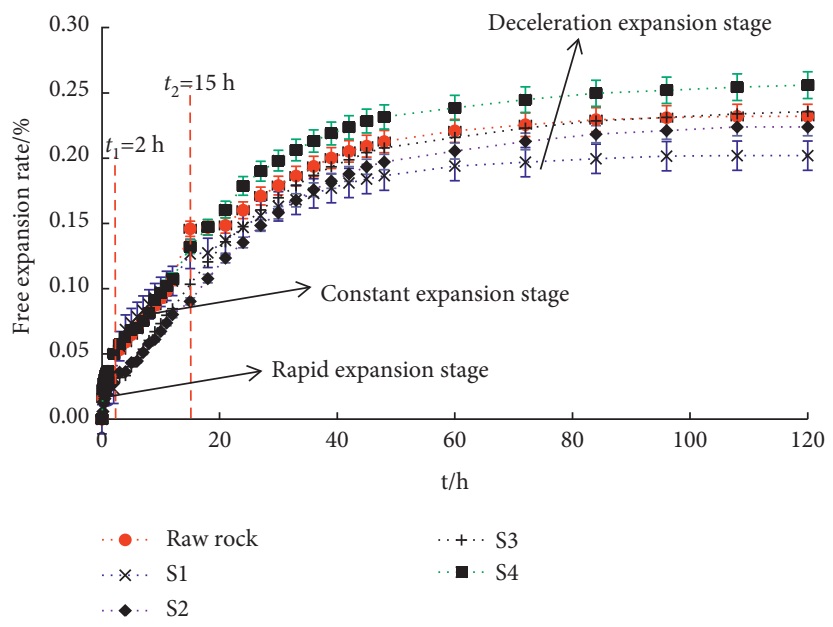

FIgURE 12: Axial expansion rate curve of silty mudstone and similar materials.

TABLE 18: Basic physical parameters of similar material samples and raw rock samples.

\begin{tabular}{|c|c|c|c|c|c|c|}
\hline Scheme & Mass (g) & Diameter $(\mathrm{cm})$ & Hight $(\mathrm{cm})$ & Volume $\left(\mathrm{cm}^{3}\right)$ & Dry density $\left(\mathrm{g} / \mathrm{cm}^{3}\right)$ & Porosity (\%) \\
\hline S1 & 198.28 & 5.002 & 5.012 & 98.44 & 1.68 & 43.26 \\
\hline S2 & 198.32 & 4.998 & 5.002 & 98.48 & 1.69 & 40.38 \\
\hline S3 & 198.48 & 5.006 & 5.008 & 98.52 & 1.74 & 38.54 \\
\hline $\mathrm{S} 4$ & 199.02 & 5.004 & 5.026 & 98.79 & 1.80 & 36.80 \\
\hline Raw rock & 198.72 & 5.002 & 5.028 & 98.75 & 1.73 & 38.71 \\
\hline
\end{tabular}

scheme S3 show the most similar density and porosity as the raw rock samples. This result further confirms the optimal values of water content, barite powder ratio, gypsum mass, and clay mineral ratio.

Based on the above analysis, the optimal ratios of similar materials are determined, which allows producing a similar material that has similar physical and mechanical properties as well as water-absorption and water-expansion characteristics to the mean properties of silty mudstone in the Yuelu Mountain (Changsha, China). These optimal ratios can provide referencing guidance for the design of similar materials for silty mudstone in other regions.

4.3. Microstructure of Similar Materials. SEM observations were performed on small specimens extracted from cylindrical similar material samples and raw rock samples. Figure 13 shows the SEM images of horizontal and vertical planes of similar material specimens (S1-S4) and a raw rock specimen. In SEM images, the white arrow represents barite 


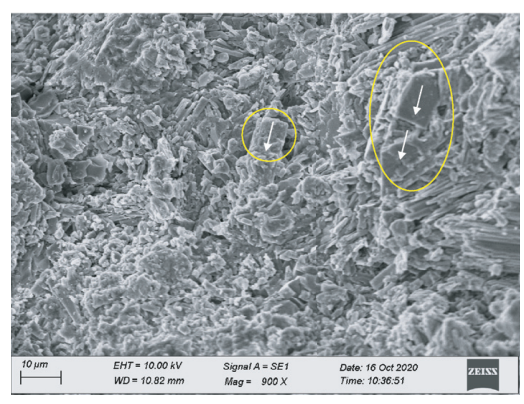

(a)

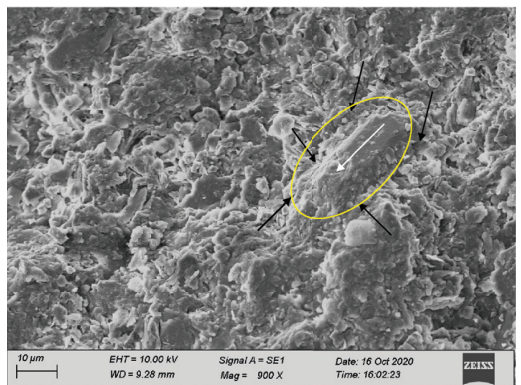

(c)

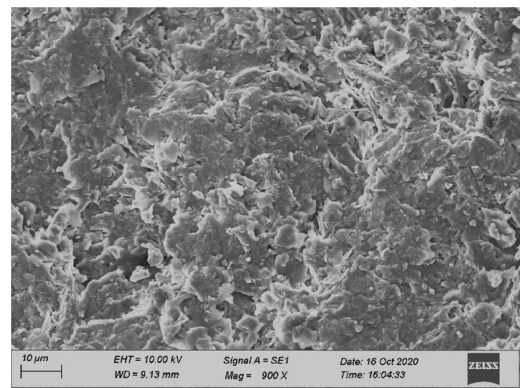

(e)

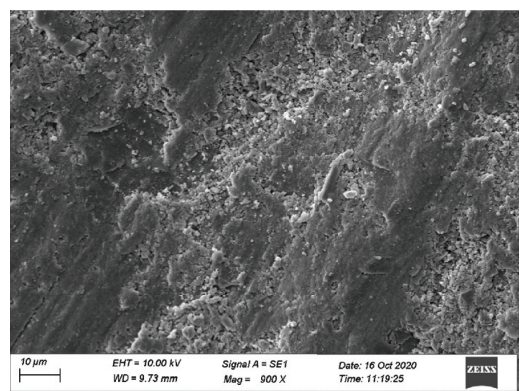

(g)

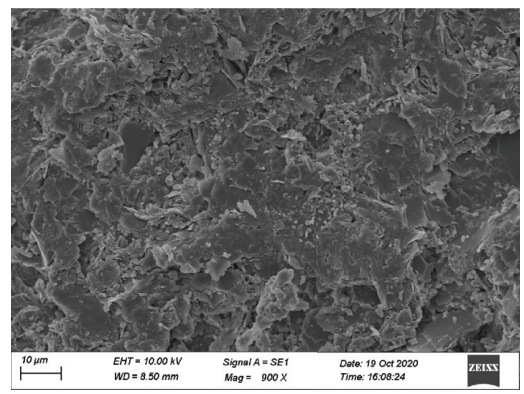

(i)

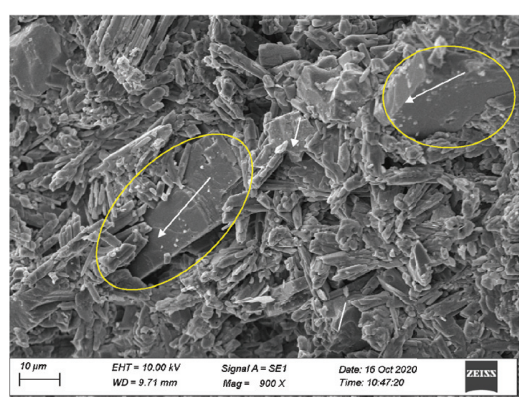

(b)

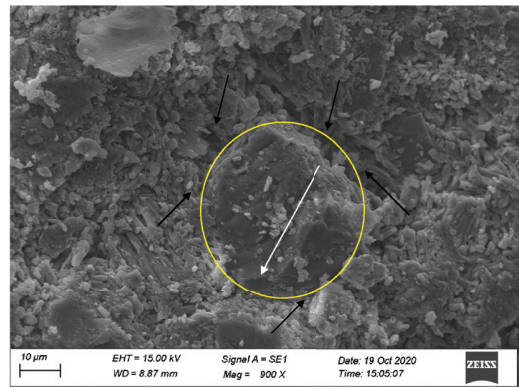

(d)

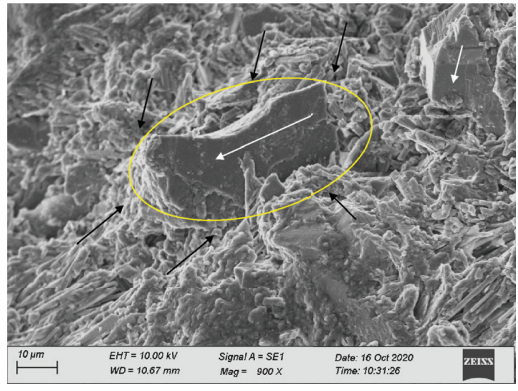

(f)

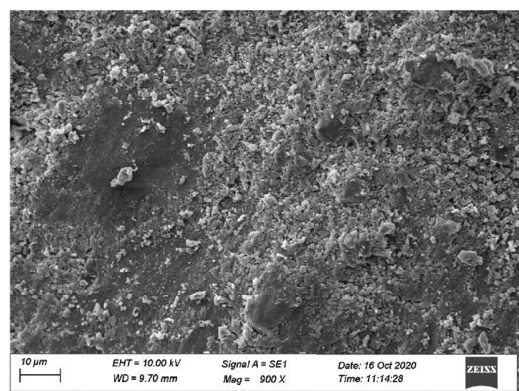

(h)

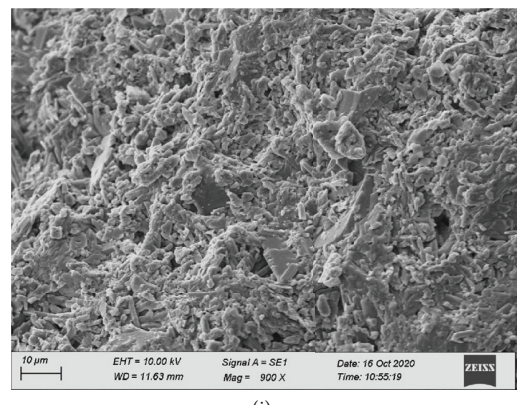

(j)

Figure 13: SEM images of raw rock and similar material specimens: (a,b) S1 specimen (0\%); (c, d) S2 specimen (6\%); (e, f) S3 specimen (12\%); (g, h) S4 specimen (18\%); (i, j) raw rock specimen. 


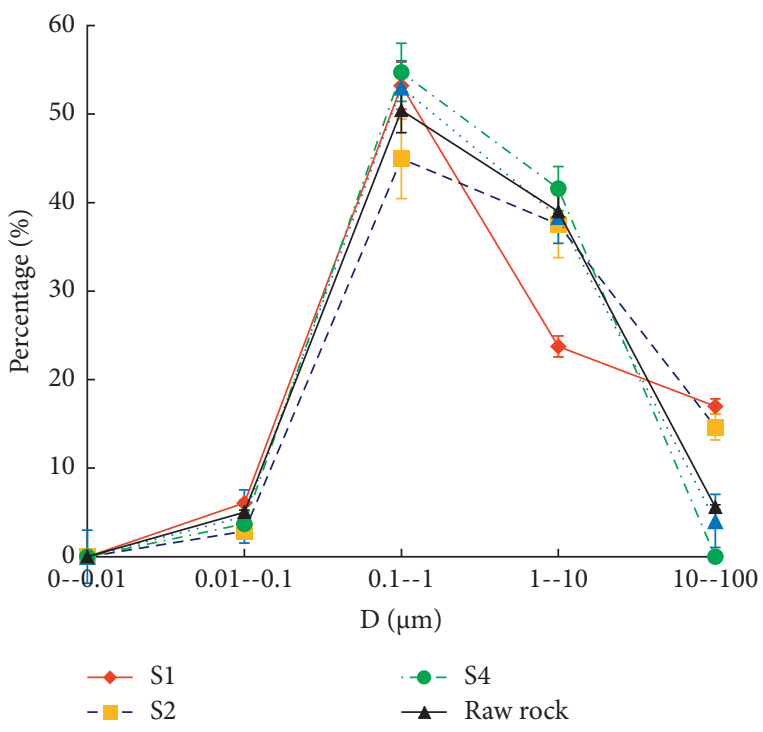

(a)

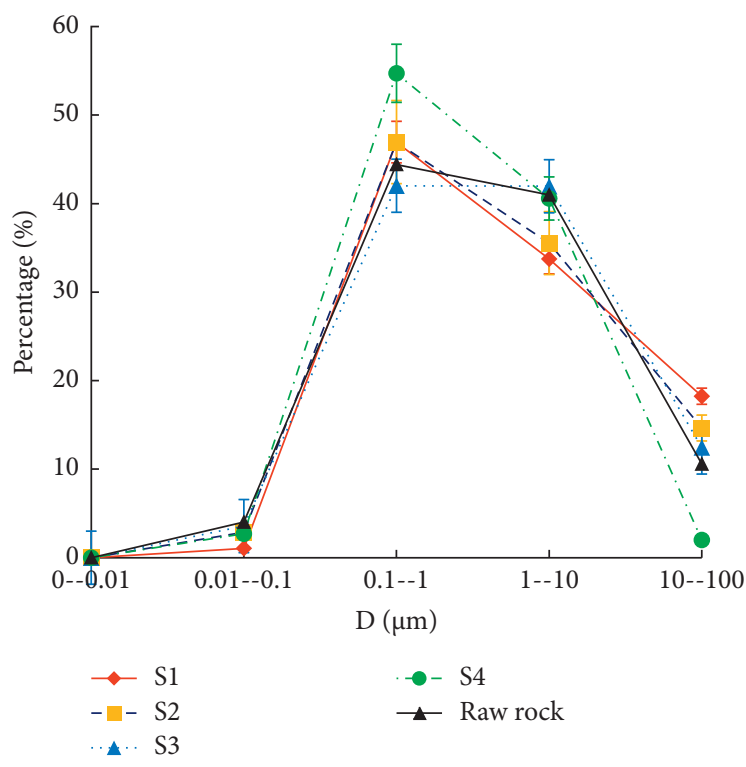

(b)

FIGURE 14: Relationship between pore area ratio and pore diameter: (a) in the horizontal plane and (b) in the vertical plane.

particles, and the black arrow represents clay mineral particles. It can be observed that when the clay mineral ratio is $0 \%$ (Figures 13(a) and 13(b)), the surface of barite particles is not fully wrapped by gypsum, and there are a lot of pores around. Due to compaction, barite particles and gypsum particles are mainly arranged face to face in the horizontal plane. Barite particles and gypsum particles mainly appear in the form of particle edge in the vertical plane, forming a large number of pores. With the increase of the clay mineral ratio, the SEM images are shown in Figures 13(c)-13(f). The pores between gypsum and barite particles are continuously filled with clay mineral particles, and the pores are fully filled in the horizontal plane; in particular, when the clay mineral ratio is $18 \%$ (Figures $13(\mathrm{~g})$ and $13(\mathrm{~h})$ ), there are almost no large pores in the horizontal plane and vertical plane. From the SEM image taken from the horizontal plane of the raw rock in Figure 13(i), it can be observed that the surface of the rock particles is flat and smooth due to sedimentation, but it still contains small primary pores. From the SEM image of the vertical plane of the raw rock sample (Figure 13(j)), it can be observed that the raw rock is formed by cementation of the raw rock particles, resulting in large pores around the particles.

It is noted that, for similar material specimens with different clay mineral ratios, the horizontal plane is very dense compared to the vertical plane, but the horizontal plane has many small primary pores in the vertical plane. This is mainly due to the pressure on the horizontal plane in the process of protolith diagenesis and sample making of similar materials, resulting in the face-to-face arrangement of particles. In the similar material specimens, with the increase of clay mineral ratio, the angular barite particles are gradually wrapped by gypsum, clay minerals, and hydration products, and the structure becomes more and more compact, and the pores decrease gradually. Finally, a dense structure without obvious pores is formed. The specific changes have been marked with ellipse in the figure. The main reasons for the above phenomena are the following: Gypsum and clay minerals gradually react with water, needle-like and rod-shaped gypsum crystals gradually disappear in the process of hydration reaction, the pores between particles are constantly filled, and the barite particles that do not participate in the hydration reaction are constantly wrapped; finally, with the hydration reaction, most of the gypsum is hydration products. The gel package has no edges and corners, forming a dense whole and a certain degree of strength. At the same time, hydration products are cemented and filled with intergranular voids, and pores are constantly reduced, forming a denser structure that plays a strong supporting role. In a word, with the increase of clay mineral ratio, the pores in the horizontal and vertical planes of similar material specimens are less and less, and the structure is more compact. When the clay mineral ratio is $12 \%$ (scheme S3), the dense structure is generated because of the hydration of gypsum and the filling of clay minerals; meanwhile, there are some pores on this basis, similar to pore morphology of the raw rock. When the clay mineral ratio is $18 \%$ (scheme S4), there are almost no pores and the structural morphology is very close in the horizontal plane and vertical plane of the similar material specimen. A quantitative analysis of the pore structures of all specimens is made based on the image processing method described in [47]; and the results are presented in Figure 14. It can be seen that most of pores in both the horizontal and vertical planes of all specimens have diameters between 0.01 and $100 \mu \mathrm{m}$. When the clay mineral ratio is $12 \%$, the pore size distribution of the similar material specimen in scheme S3 is very close to that of the raw rock specimen. 


\section{Conclusion}

Based on the physical and mechanical properties of silty mudstone, the similar materials of silty mudstone with water absorption and expansibility were developed based on traditional materials including gypsum, barite powder, clay minerals (i.e., montmorillonite, illite, and chlorite), and distilled water. Specific conclusions are as follows:

(1) The water content plays an important role in controlling the density, tensile strength, and elastic modulus of the similar material samples. The effect of barite powder ratio on the uniaxial compressive strength was significant. Gypsum mass also has a significant effect on the density of similar materials.

(2) For similar materials with the proposed mixing ratios, the density is $1.82-2.08 \mathrm{~g} / \mathrm{cm}^{3}$, the uniaxial compressive strength is $8.28-18.19 \mathrm{MPa}$, the tensile strength is $1.01-4.00 \mathrm{MPa}$, the elastic modulus is $1.01-2.38 \mathrm{GPa}$, and Poisson's ratio is $0.20-0.40$. Similar materials produced at a water content of $19 \%$, a barite powder ratio of $32 \%$, and a gypsum mass of $250 \mathrm{~g}$ show the best similarity to the raw rock in terms of physical and mechanical properties.

(3) The optimal mixing ratios were finally identified based on the results of the secondary refinement tests. Except for the optimal water content of $19 \%$, optimal barite powder ratio of $32 \%$, and optimal gypsum mass of $250 \mathrm{~g}$, the optimal clay mineral ratio is $12 \%$. These optimal ratios can provide referencing guidance for the design of similar materials for silty mudstone in other regions.

(4) The raw rock surface is very dense, but there are many small primary pores. With the increase of clay mineral ratio, the absorption of similar materials increases continuously. The pores in similar material samples with a clay mineral ratio of $12 \%$ are filled by gypsum hydration products and clay minerals; thus, these similar material samples have similar water absorption and water expansion to those of the raw rock.

\section{Data Availability}

Some or all data, models, or codes that support the findings of this study are available from the corresponding author upon reasonable request.

\section{Conflicts of Interest}

The authors declare that they have no conflicts of interest.

\section{Acknowledgments}

The authors acknowledge the financial supports received from the National Natural Science Foundation of China (nos. 51838001, 51878070, 51908069, and 51908073), the Key Research and Development Program of Hunan Province (no. 2019SK2171), the Open Fund of National Engineering
Laboratory of Highway Maintenance Technology, Changsha University of Science and Technology (no. kfj170103), and the Research and Innovative Program for Graduates of Hunan Province (no. CX20190654).

\section{References}

[1] T. Hamza and T. K. Raghuvanshi, "GIS based landslide hazard evaluation and zonation - a case from Jeldu district, central Ethiopia," Journal of King Saud University Science, vol. 29, no. 2, pp. 151-165, 2017.

[2] T. K. Raghuvanshi, "Plane failure in rock slopes-a review on stability analysis techniques," Journal of King Saud University Science, vol. 31, no. 1, pp. 101-109, 2019.

[3] L. Zeng, F. Li, Q.-F. Gao, X. Yao, and G. Wang, "Insight into the fracturing of silty mudstone in cyclic hydrothermal environments based on computed tomography," Transportation Geotechnics, vol. 26, Article ID 100432, 2021.

[4] C. Y. Jia, H. L. Wang, X. Z. Sun et al., "Similar material simulation test of overlying strata characteristics of isolated working face mining with thick-hard strata," Geotechnical \& Geological Engineering, vol. 38, no. 2, pp. 1121-1132, 2019.

[5] Z.-H. Li, Q. Lou, E.-Y. Wang, S.-J. Liu, and Y. Niu, "Study on acoustic-electric-heat effect of coal and rock failure processes under uniaxial compression," Journal of Geophysics and Engineering, vol. 15, no. 1, pp. 71-80, 2018.

[6] B. Zhang, H. Wang, L. Yuan, S. Li, and Z. Liu, "Ultra-low permeability rock-analogue material for gas-solid coupling model tests," International Journal of Physical Modelling in Geotechnics, vol. 21, no. 2, pp. 85-97, 2021.

[7] R. Phillips and K. Chi, "Modelling ice rubble-rock berm interaction," International Journal of Physical Modelling in Geotechnics, vol. 15, no. 1, pp. 35-43, 2015.

[8] J. Zhang, J. Peng, L. Zeng, J. Li, and F. Li, "Rapid estimation of resilient modulus of subgrade soils using performance-related soil properties," International Journal of Pavement Engineering, vol. 22, no. 6, pp. 732-739, 2019.

[9] P. Zhao, R. Zhuo, S. Li, and H. Lin, "Experimental research on the properties of "solid-gas" coupling physical simulation similar materials and testing by computer of gas in coal rock," Wireless Personal Communications, vol. 102, no. 2, pp. 1539-1556, 2018.

[10] Q. Liu, S. Chen, S. Wang, J. Chai, and D. Zhang, "Experimental development process of a new cement and gypsumcemented similar material considering the effect of moisture," Geofluids, vol. 2020, Article ID 8831801, 14 pages, 2020.

[11] J. Zhang, Z. Wang, and Z. Song, "Numerical study on movement of dynamic strata in combined open-pit and underground mining based on similar material simulation experiment," Arabian Journal of Geosciences, vol. 13, no. 16, pp. 1-15, 2020.

[12] G. Lu, H. Wang, Y. Zhang et al., "The hydro-mechanical interaction in novel polyurethane-bound pervious pavement by considering the saturation states in unbound granular base course," International Journal of Pavement Engineering, vol. 2021, Article ID 1915490, 2021.

[13] J.-j. Wang, Z.-n. Shi, L. Zeng, and S.-x. Qi, "The effects of different nanoadditives on the physical and mechanical properties of similar silty mudstone materials," Advances in Civil Engineering, vol. 2020, Article ID 8850436, 11 pages, 2020.

[14] Z.-W. Deng, Q.-F. Gao, H. Dong, and L.-X. Li, "Dynamic responses of the shallow foundation of an onshore wind 
turbine," International Journal of Physical Modelling in Geotechnics, vol. 19, no. 5, pp. 247-260, 2019.

[15] C.-1. Dong, G. Zhao, X. Lu, X. Meng, Y. Li, and X. Cheng, "Similar simulation device for unloading effect of deep roadway excavation and its application," Journal of Mountain Science, vol. 15, no. 5, pp. 1115-1128, 2018.

[16] X. M. Shi, B. G. Liu, Y. Y. Xiang, and Y. Qi, "A Method for selecting similar materials for rocks in scaled physical modeling tests," Journal of Mining Science, vol. 54, no. 6, pp. 938-948, 2018.

[17] X. Yang, C. Y. Zhou, Z. Liu et al., "Experimental study on mix proportion of similar materials for weathered mudstone," Chinese Journal of Rock Mechanics and Engineering, vol. 35, no. 3, pp. 549-557, 2016.

[18] Z. M. Chen and Y. S. Fen, "Study on similar materials of carbonaceous phyllite," Bulletin of the Chinese Ceramic Society, vol. 36, no. 12, pp. 4234-4241, 2017.

[19] X. Wang, X. Liu, E. Wang et al., "Experimental research of the AE responses and fracture evolution characteristics for sandparaffin similar material," Construction and Building Materials, vol. 132, pp. 446-456, 2017.

[20] S. Liu and W. Liu, "Experimental development process of a new fluid-solid coupling similar-material based on the orthogonal test," Processes, vol. 6, no. 11, p. 211, 2018.

[21] S. Q. He, L. Z. Jin, S. N. Ou, and X. H. Ming, "Soft coal solidgas coupling similar material for coal and gas outburst simulation tests," Journal of Geophysics and Engineering, vol. 15, no. 5, pp. 2033-2046, 2018.

[22] B. Haimson and J. Ovacich, "Borehole instability in highporosity Berea sandstone and factors affecting dimensions and shape of fracture-like breakouts," Engineering Geology, vol. 69, no. 3, pp. 219-231, 2003.

[23] W.-b. Sun, F. Zhou, J.-l. Shao, H.-q. Du, and Y.-c. Xue, "Development status and prospects of mine physical similar material simulation experiments," Geotechnical \& Geological Engineering, vol. 37, no. 4, pp. 3025-3036, 2019.

[24] J. G. Wang, W. F. Liu, B. Liang et al., "On the similar material for creep characteristic study of weak and broken oil shale," Journal of Experimental Mechanics, vol. 31, no. 2, pp. 263-268, 2016.

[25] Z. F. Chu, B. G. Liu, D. R. Ren et al., "Development of rheology similar material of soft rock and its application in mode," Rock and Soil Mechanics, vol. 40, no. 6, pp. 2172-2182, 2019.

[26] X. H. Diao, K. Wang, and P. Y. Fu, "Study on proportioning of similar material to swelling rock," Applied Mechanics and Materials, vol. 501-504, pp. 439-443, 2014.

[27] Y. B. Ning, H. M. Tang, B. C. Zhang et al., "Research on rock similar material proportioning test based on orthogonal design and its application in base friction physical model test," Rock and Soil Mechanics, vol. 41, no. 6, pp. 1-11, 2019.

[28] J. J. Xie, T. H. Chen, H. B. Liu, and Q. Xie, "Development and application of palygorskite clays from Jiangsu and Anhui provinces," Bulletin of the Chinese Ceramic Society, vol. 46, no. 5, pp. 746-754, 2018.

[29] W. Yang, R. P. Chen, and X. Chen, “Application of molecular dynamics simulation method in micro-properties of clay minerals," Chinese Journal of Geotechnical Engineering, vol. 41, no. 1, pp. 181-184, 2019.

[30] Editorial Board of Engineering Geology Handbook, Engineering Geology Handbook, China Building Industry Press, Beijing, China, 5th edition, 1992.

[31] H. Zhou, J. Chen, C. Q. Zhang, Y. Zhu, J. Lu, and Y. Jiang, "Experimental study of the rockburst model material with low-strength and high-brittleness," Rock and Soil Mechanics, vol. 40, no. 6, pp. 2039-2049, 2019.

[32] Z. Li, Z. Li, T. T. Nguyen, and S. Chen, "Orthogonal chemical reaction optimization algorithm for global numerical optimization problems," Expert Systems with Applications, vol. 42, no. 6, pp. 3242-3252, 2015.

[33] S. Zhang, G. Fan, D. Zhang, M. Chen, and C. Zhang, "Study on material properties and similar material proportion of weakly cemented water-resisting strata," Arabian Journal of Geosciences, vol. 12, no. 11, p. 340, 2019.

[34] L. Zeng, H.-C. Yu, J. Liu, Q.-F. Gao, and H.-B. Bian, "Mechanical behaviour of disintegrated carbonaceous mudstone under stress and cyclic drying/wetting," Construction and Building Materials, vol. 282, p. 122656, 2021.

[35] L. Zeng, J.-T. Luo, J. Liu, Q.-F. Gao, and H.-B. Bian, "Disintegration characteristics and mechanisms of carbonaceous mudstone subjected to load and cyclic drying-wetting," Journal of Materials in Civil Engineering, vol. 33, no. 8, Article ID 04021195, 2021.

[36] E. Hoek, D. Wood, and S. A. Shah, "A modified Hoek-Brown failure criterion for jointed rock masses," in Proceedings of the Rock Characterization Symposium of ISRM, Thomas Telford Publishing, London, UK, September 1992.

[37] L. Zeng, L. Xiao, J. Zhang, and $\mathrm{H}$. Fu, "The role of nanotechnology in subgrade and pavement engineering: a review," Journal of Nanoscience and Nanotechnology, vol. 20, no. 8, pp. 4607-4618, 2020.

[38] P. Mielke, K. Bär, and I. Sass, "Determining the relationship of thermal conductivity and compressional wave velocity of common rock types as a basis for reservoir characterization," Journal of Applied Geophysics, vol. 140, pp. 135-144, 2017.

[39] P. Yan, C. Zhang, Q. Gao, and W. Lu, "Acoustic wave test on mechanical properties variation of rocks under different damage degrees," Rock and Soil Mechanics, vol. 36, no. 12, pp. 3425-3432, 2015.

[40] L. Zeng, X. Yao, J. Zhang, Q.-F. Gao, J. Chen, and Y. Gui, "Ponded infiltration and spatial-temporal prediction of the water content of silty mudstone," Bulletin of Engineering Geology and the Environment, vol. 79, no. 10, pp. 5371-5383, 2020.

[41] Z. Song, Y. Cheng, X. Tian, J. Wang, and T. Yang, "Mechanical properties of limestone from Maixi tunnel under hydromechanical coupling," Arabian Journal of Geosciences, vol. 13, no. 11, pp. 1-13, 2020.

[42] GB/T 2013, Standard for Test Methods of Engineering Rock Mass GB/T 50266-2013, China Planning Press, Beijing, China, 2013.

[43] M. C. Acar, Z. Gündüz, and H. B. Kara, "Modulus of elasticity determination of rocks using compressometer, strain gauge and LVDT," in Proceedings of ACE 2014 11th International Congress on Advances in Civil Engineering, vol. 11, pp. 1-6, Istanbul, Turkey, October 2014.

[44] E. Komurlu, F. Cihangir, A. Kesimal, and S. Demir, "Effect of adhesive type on the measurement of modulus of elasticity using electrical resistance strain gauges," Arabian Journal for Science and Engineering, vol. 41, no. 2, pp. 433-441, 2016.

[45] JTG 2005, Test Methods of Rock for Highway Engineering JTG E41-2005, Ministry of Transport of the People's Republic of China, Beijing, China, 2005.

[46] Q.-F. Gao, F. Zeng, Z.-N. Shi, and R. Zhang, "Evolution of unsaturated shear strength and microstructure of a compacted silty clay on wetting paths," International Journal of Geomechanics, 2021. 
[47] Q. Gao, Z. Shi, J. Luo, and J. Liu, "Microstructural insight into permeability and water retention property of compacted binary silty clay," Journal of Central South University, vol. 27, no. 7, pp. 2068-2081, 2020.

[48] Q. F. Gao, M. Jrad, M. Hattab, F. Jean-Marie, and A. Lamine Ighil, "Pore morphology, porosity, and pore size distribution in kaolinitic remolded clays under triaxial loading," International Journal of Geomechanics, vol. 20, no. 6, Article ID 04020057, 2020.

[49] H. Y. Fu, J. C. Chen, L. Zeng, and X. Qiu, "Experiment on the effects of temperature and humidity on uniaxial mechanical properties of silty mudstone," China Civil Engineering Journal, vol. 52, no. 1, pp. 89-98, 2019. 